\title{
Spatial and Direction-Based Characterization of Microstructures and Microhardness of TA15 Titanium Alloy Produced by Electron Beam Melting
}

\author{
Jiangtao Ran ${ }^{1}$, Xiaojing Sun ${ }^{2}$, Shiliang Wei ${ }^{3}$, Zhuo Chen ${ }^{4}$ and Hong Zhao ${ }^{1,4, *}$ \\ 1 College of Mechanical and Electrical Engineering, Harbin Engineering University, Harbin 150001, China; \\ 653099183@hrbeu.edu.cn \\ 2 College of Materials Science and Chemical Engineering, Harbin Engineering University, \\ Harbin 150001, China; sunxiaojing@hrbeu.edu.cn \\ 3 Mechanical \& Power Engineering College, Harbin University of Science and Technology, \\ Harbin 150001, China; weishiliang@hrbeu.edu.cn \\ 4 Aerospace Hiwing (Harbin) Titanium Industry Co., Ltd., Harbin 150001, China; cccccczhuo@163.com \\ * Correspondence: zhaohong_heu@163.com; Tel.: +86-13904511866
}

Citation: Ran, J.; Sun, X.; Wei, S.;

Chen, Z.; Zhao, H. Spatial and

Direction-Based Characterization of

Microstructures and Microhardness of TA15 Titanium Alloy Produced by Electron Beam Melting. Crystals 2021, 11,495. https://doi.org/10.3390/ cryst11050495

Academic Editors: Sergio Brutti and Raghvendra Singh Yadav

Received: 13 April 2021

Accepted: 26 April 2021

Published: 29 April 2021

Publisher's Note: MDPI stays neutral with regard to jurisdictional claims in published maps and institutional affiliations.

Copyright: (c) 2021 by the authors. Licensee MDPI, Basel, Switzerland. This article is an open access article distributed under the terms and conditions of the Creative Commons Attribution (CC BY) license (https:// creativecommons.org/licenses/by/ $4.0 /)$
Abstract: The extracted position and characterization direction of specimens have an unignorable effect on the microstructural characteristics of materials produced by electron beam melting (EBM). This study focused on the effects of extracted position and characterization direction on the microstructure, defect distribution and Vickers hardness of TA15 titanium alloy fabricated by electron beam melting. Results show that the microstructure at the bottom end of TA15 specimens is coarser and hot cracks are visible at this end. Grain morphology in longitudinal direction is columnar while that in transversal direction is chessboard-like. The results of defect analysis show that gas pores are visible in transversal direction while lack of fusion exists in longitudinal direction. The average relative density of TA15 specimens in transversal direction is higher than that in longitudinal direction. The results of energy spectrum analysis show that there is evaporation of Al during the forming process, but no elements segregation and enrichment are observed. This study provides important insights on the microstructure analysis and defect evaluation of materials made by EBM technology.

Keywords: titanium alloys; electron beam melting; microstructure; characterization direction; defects; microhardness

\section{Introduction}

Electron beam melting (EBM) technology is a kind of additive manufacturing technology widely used in the aerospace field, which can form high-performance metal parts with complex shapes [1-7]. Titanium alloy is one of the most widely investigated and used materials in EBM. The microstructure and mechanical properties of Ti-6Al-4V alloy have been investigated and reported by numerous investigations. Murr et al. [8,9] has reported that the typical microstructure of EBM Ti-6Al-4V is acicular and lamellar $\alpha$ phase together with a small amount of $\beta$ phase. Tan et al. $[10,11]$ has revealed the martensitic transformation in the EBM fabrication of Ti-6Al-4V, indicating the existence of martensite. Zhang et al. [12] claimed that abundant $\alpha$ lamellae with six variants were presented inside the columnar prior- $\beta$ grains and they observed multiple sub-variants in each $\alpha$ variant for the first time. Their valuable research showed that the relative amount of six $\alpha$ variants could account for the anisotropy in the mechanical properties. Many factors such as process parameters [13-15], scanning strategies [16-18], build orientation [13,19-24], heat treatments [25-29] and hot isostatic pressing [28,30-33] affect the microstructure and mechanical properties of EBM Ti-6Al-4V. Besides, columnar prior $\beta$-grains were found to epitaxially grow through a few layers and their major axis was found to orient parallel to the build direction $[2,11,12,23,26,34-36]$. 
The microstructures and mechanical properties of TiAl-based alloys were also discussed and investigated by numerous investigations. Yue et al. $[7,37,38]$ investigated the process window, defects, microstructures, heat treatment as well as tensile properties at room and elevated temperatures of Ti-47Al-2Cr-2Nb alloy. Wimler et al. [39] reported the development of novel process-adapted $\gamma$-TiAl based alloys, showing that it was possible to produce reliable high-performance TiAl components by the use of proper parameters in combination with subsequent heat treatments. Lee et al. [40,41], Lin et al. [42] and Biamino et al. [43] investigated the microstructure, compressive deformation, tensile properties, creep resistance of Ti-48Al-2Cr-2 $\mathrm{Nb}$ alloy in great detail. Kan et al. [44] investigated the microstructural degradation of Ti-45Al-8Nb alloy and Juechter et al. [45] discussed the performance optimization of Ti-45Al-4Nb-C alloy by optimizing scanning strategy and introducing heat treatments.

Build height is an important factor that affects the microstructure and mechanical properties of EBM materials. Murr et al. [8] reported that the average acicular $\alpha$-plate thickness was $3.2 \mu \mathrm{m}$ in the top region of the EBM Ti-6Al-4V specimen while that was $1.6 \mu \mathrm{m}$ in the bottom region. A slight variation in both $\beta$ grain size and $\alpha$ lath thickness at different heights was identified by Galarraga et al. [36], showing that the $\alpha$ lath thickness of EBM Ti-6Al-4V decreased as the build height increased. Tan et al. [46] discovered that both prior $\beta$ grain width and $\beta$ phase interspacing of EBM Ti-6Al-4V continuously increased with build height. Wang et al. [47] claimed that the $\alpha+\beta$ microstructure of EBM Ti-6Al-4V finer with the increase of build height. Al-Bermani et al. [48] discovered that the presence of martensite was seen at the top of 2-mm-tall and 5-mm-tall EBM Ti-6Al-4V samples, while it was not evident at the top of an 18-mm-tall Ti-6Al-4V sample. Hrabe et al. [49] reported a trend of increasing $\alpha$ lath thickness with increasing build height. It should be noted that there is no conclusive result about the evolving trend of the microstructure when increasing build height.

Microhardness is an important indicator to evaluate the mechanical properties of materials. There remain some disputes regarding the relationship between build height and microhardness. For EBM Ti-6Al-4V, Bruno et al. [20] and Wang et al. [47] found that the microhardness increased with the increase of build height. Tan et al. [46] claimed that the microhardness has decreased with the increase of build height. Galarraga et al. [36] and Hrabe et al. [49] demonstrated that there was no obvious relationship between build height and microhardness.

TA15 alloy, which is a kind of near $\alpha$ titanium alloy, has been widely applied in aerospace application due to its good combination of excellent welding ability and mechanical properties at elevated temperature. However, it is still extremely challenging for conventional machining, casting and forging technologies to fabricate complex-shape TA15 titanium alloys. Metal additive manufacturing technology arises at the historic moment. Electron beam melting (EBM) and selective laser melting (SLM) are common metal additive manufacturing technologies. SLM technology has been successfully adopted to manufacture TA15 titanium alloys parts. Jiang et al. [50] fabricated nearly fully dense TA15 samples $(99.98 \%)$ by utilizing SLM technology with the optimized processing parameters. Wu et al. [51] successfully prepared TA15 samples with ultrafine crystallites and numerous nano-scale twins by the use of SLM technology. Xu et al. [52] had carried out an investigation on the tensile fracture properties of EBM TA15 specimen. However, there is still little investigation about the microstructure of TA15 specimens built with EBM technology. So, this study focused on the microhardness and various microstructures of metallurgical samples extracted from different positions of one same EBM TA15 sample. By investigating the microstructure and microhardness properties of different locations on samples, some new insights are provided for the microstructure characterization of EBM parts. 


\section{Materials and Methods}

\subsection{Materials and Processing Conditions}

The precursor powders used in this investigation were gas atomized TA15 spherical powders provided by Aerospace Hiwing (Harbin) Titanium Industry Co., Ltd. (Harbin, China). These powders had a content of $50 \%$ reused and $50 \%$ new powders. Table 1 shows the chemical composition of TA15 titanium alloy powders.

Table 1. Chemical composition of TA15 titanium alloy powder.

\begin{tabular}{ccccccccccc}
\hline Element & Ti & Al & Zr & V & Mo & Si & C & O & N & H \\
\hline wt. $\%$ & balance & 6.72 & 2.26 & 2.30 & 1.84 & 0.014 & 0.022 & 0.069 & 0.0055 & 0.0025 \\
\hline
\end{tabular}

Figure 1 shows the morphology of TA15 powders, it should be noticed that there were some powders with irrugular shape, which was marked by red dotted circles. This phenomenon was also reported by [20] when reused Ti-6Al-4V powders were adopted to build specimens. Figure 2 is an illustration showing the formation of irregular-shape powders. In order to reduce spheroidization and temperature gradient, defocused electron beams were used to preheat the newly added powders during the building process. The energy of these electron beams was too low to completely melt these metal powders. As a result, the metal powders were partially melted. The relatively smaller powders within the metal powders were melted, which acted as a binder to bond those relatively larger powders together, as is shown in Figure 2. When the building process was finished, the powder recovery system was used to purge the remaining unmelted powders. Under the action of high-velocity air flow, these metal powders connected by sintering necks were purged into irregular pieces.

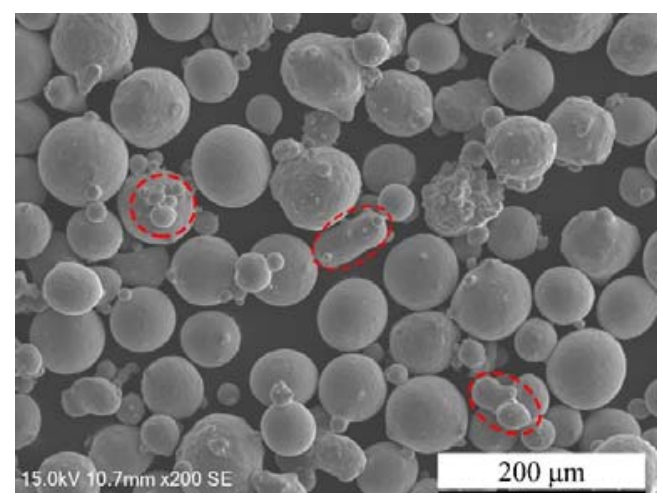

Figure 1. Scanning electron microscope morphology of initial TA15 powders.

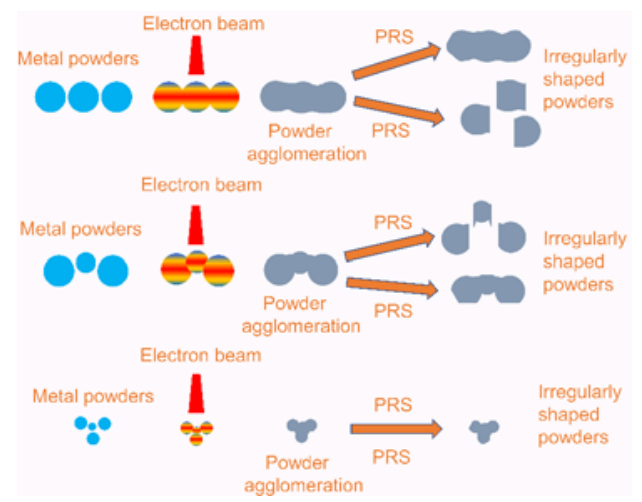

Figure 2. Schematic diagram showing the formation of irregular-shape powders. 
Table 2 shows detailed processing parameters used for building TA15 specimens during the EBM process. The EBM Q20 machine (Arcam AB, Sweden, software version 5.2, layer thickness $90 \mu \mathrm{m}$, accelerating voltage $60 \mathrm{kV}$ ) was used to manufacture TA15 specimens.

Table 2. Process parameters used for building TA15 specimens in this study.

\begin{tabular}{cccc}
\hline EBM Parameters & Outer Contour & Inner Contour & Hatch Filling \\
\hline Beam speed $(\mathrm{mm} / \mathrm{s})$ & 450 & 450 & 4530 \\
Beam current $(\mathrm{mA})$ & 9 & 9 & 15 \\
\hline Max current $(\mathrm{mA})$ & 9 & 9 & 28 \\
\hline Focus offset $(\mathrm{mA})$ & 6 & 6 & 45 \\
\hline Beam pattern & spot & spot & snake \\
\hline Speed factor & $\ldots$ & 0.18 & 36 \\
\hline Line offset $(\mathrm{mm})$ & 0.27 & 0.20 \\
\hline
\end{tabular}

Table 2. EBM: Prior to the start of the EBM process, the base plate was heated by applying defocused electron beam until the thermocouple underneath reached a temperature of $700{ }^{\circ} \mathrm{C}$. All powder layers added during the build process were preheated with the same preheating parameters throughout. A layer thickness of $90 \mu \mathrm{m}$ was adopted in this study. All TA15 specimens were directedly built on the base plate without any supporting structures. In the cooling stage, the cooling rate was increased by injecting high purity helium gas. All specimens were built in one batch with no heat treatments or hot isostatic pressing.

\subsection{Sample Location and Preparation}

Figure 3 shows the preparation and characterization of TA15 specimens. One $100-\mathrm{mm}-$ tall TA15 specimen was fabricated by EBM technology. Then, this specimen was cut into 10 pieces and each piece was successively marked with the number from 1 to 10 . For specimen No. 1, the top surface, bottom surface and side surface were characterized. From specimen No. 2 to No. 10, the top surface and side surface were characterized. In this way, the microstructure and Vickers hardness of these specimens in two directions (direction parallel and perpendicular to build direction) can be characterized. For the convenience of description, the direction parallel to the build direction was termed as longitudinal direction, while the direction perpendicular to the build direction was termed as transversal direction.

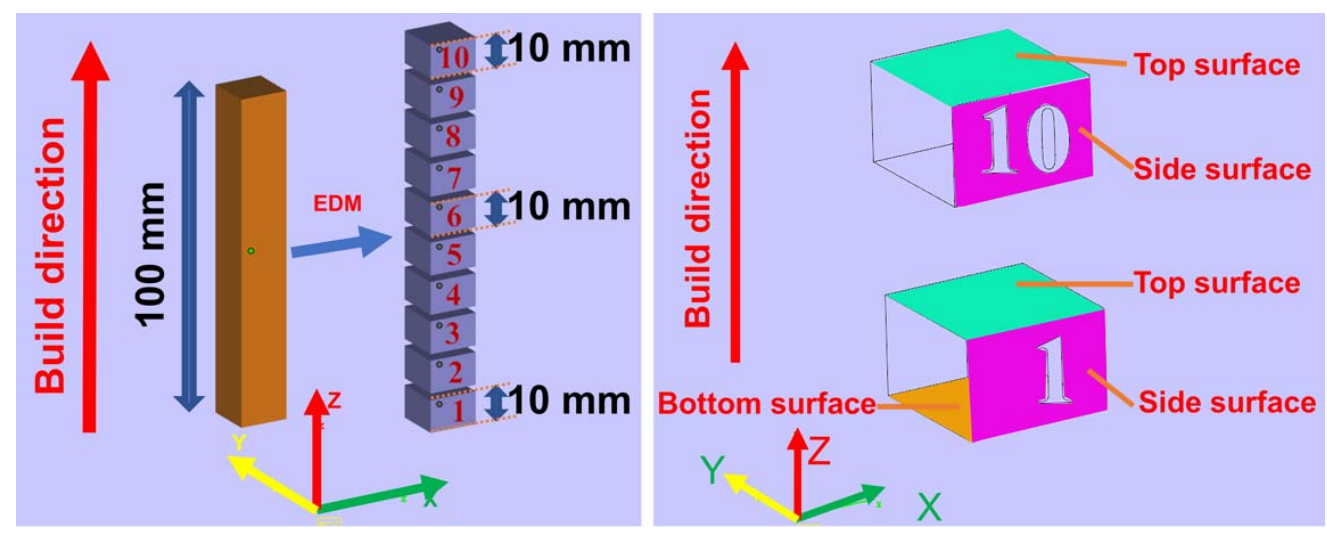

Figure 3. The preparation and characterization schematic diagram of TA15 titanium alloy.

\subsection{Characterization Methodology}

\subsubsection{Microstructure and Porosity Characterization}

No. 1 to No. 10 TA15 specimens were cut from the whole TA15 specimen by electrical discharge machining. These specimens were grounded with water-proof sandpapers (80 \# 
to 5000 \#) and polished with colloidal suspension (Struers $50 \mathrm{~nm}$, Cleveland, OH, USA). For porosity observation and evaluation, these specimens were only polished so as to avoid the formation of etch pits. DMI 5000 M (Shenyang Changxiao Instrument Co., Ltd., Shenyang, China) metallographic microscope was used to measure the porosity with a magnification of $50 \times 20$ micrographs were obtained at this magnification with the same light condition for each TA15 specimen. These 20 micrographs were randomly taken from the same plane for each TA15 specimen so as to evaluate the average porosity rate. For comparison consideration, two orientations, namely the transversal direction (normal to the build direction) and longitudinal direction (parallel to the build direction) were characterized. Image-J software (V1.8.0.112, National Institutes of Health, Bethesda, MD, USA) was adopted to deal with these micrographs with the same threshold. The porosity rate is defined as the ratio between the pixels of porosity and the pixels of the corresponding micrograph.

Kroll's reagent (a solution containing $10 \mathrm{~mL} \mathrm{HF}, 30 \mathrm{~mL} \mathrm{HNO}_{3}$ and $70 \mathrm{~mL}$ distilled water) was used to etch these TA15 specimens about $15 \mathrm{~s}$. DMI 5000M (Shenyang Changxiao Instrument Co., Ltd., Shenyang, China) optical microscope and FE-SEM SU5000 (Hitachi High Technologies corporation, Shanghai, China) scanning electron microscope were used for microstructure observation and evaluation. For specimen No. 1, microstructures of the top surface, bottom surface and side surface were characterized. As for specimen No. 2 to No. 10, microstructures of the top surface and side surface were characterized.

\subsubsection{Microhardness}

The surface finish of samples has a significant effect on the accurate measurement of Vickers hardness. As a result, all these metallographic specimens were polished but not etched. TMVS-1S (Future technology, Beijing, China) digital microhardness tester was used to measure the Vickers hardness of these TA15 specimen in two orientations with a load of $9.8 \mathrm{~N}$ dwelled for $15 \mathrm{~s}$. Five measurements were taken for each sample. For specimen No. 1, Vickers hardness of the top surface, bottom surface as well as side surface were characterized. As for specimen No. 2 to No. 10, Vickers hardness of the top surface and side surface were characterized.

\section{Results}

\subsection{Phases of TA15 Specimens Fabricated by Electron Beam Melting}

Figure 4 shows the X-ray diffraction (XRD) patterns of TA15 specimens fabricated by EBM. Specimen No. 1, No. 5 and No. 10 were taken from the bottom end, middle end and top end of a 100-mm-tall TA15 specimen, respectively. Thus, these three metallographic specimens can present the evolving trend of phases corresponding to the build height.
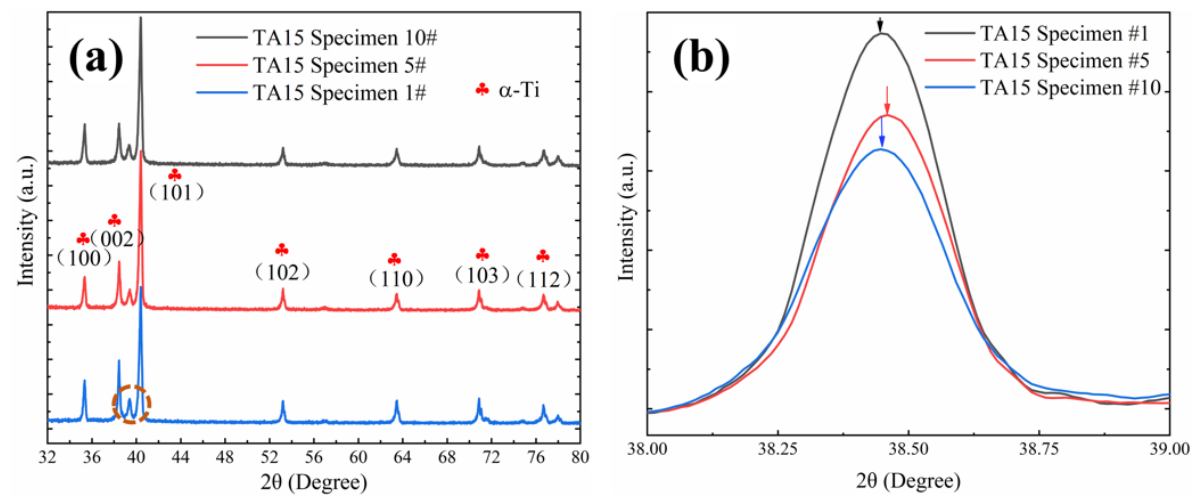

Figure 4. X-ray diffraction patterns of EBM TA15 specimen (a) and the enlarged views of selected area $(\mathbf{b})$.

It can be seen from the XRD patterns in Figure 4 that the diffraction peaks of these three TA15 samples all reflect characteristics of the close-packed hexagonal structure and no diffraction peaks of $\beta$ phase are observed. Jiang et al. [50] has proved that these diffraction 
peaks originate from titanium. The diffraction peaks of these three samples are similar to each other, indicating that the constituent phases of metallographic samples extracted from different build heights of one same sample is almost identical.

\subsection{Microstructure in Longitudinal Direction of EBM TA15 Specimen}

Figures 5 and 6 show the porosity distribution and its morphology in longitudinal direction of No. 1, No. 4, No. 7 and No. 10 TA15 specimen. It is evident that the porosity distribution of these four specimens is different from each other. The number and size of pores of No. 7 TA15 specimen are the least compared to the other three specimens. Pores are unevenly distributed on the measured surface, and their morphology is also irregular. Pores with a large size are easier to have adverse effects on the mechanical properties of metallic materials. Thus, the pores with a larger size are selected and characterized, which are shown in Figure 5(a1-a4,b1-b4) and Figure 6(a1-a4,b1-b4). Most of these pores are oval-like in shape. The major axis of these holes with large size presents a specific angle with the build direction. Generally, this type of defect is considered as lack of fusion, which is attributed to the insufficient energy input during the building process. There are two possible reasons accounted for the insufficient energy input. On the one hand, improper process parameters may lead to insufficient energy density, leading to the formation of defects. On the other, an electromagnetic interference could also lead to insufficient energy density input during the build process [36].
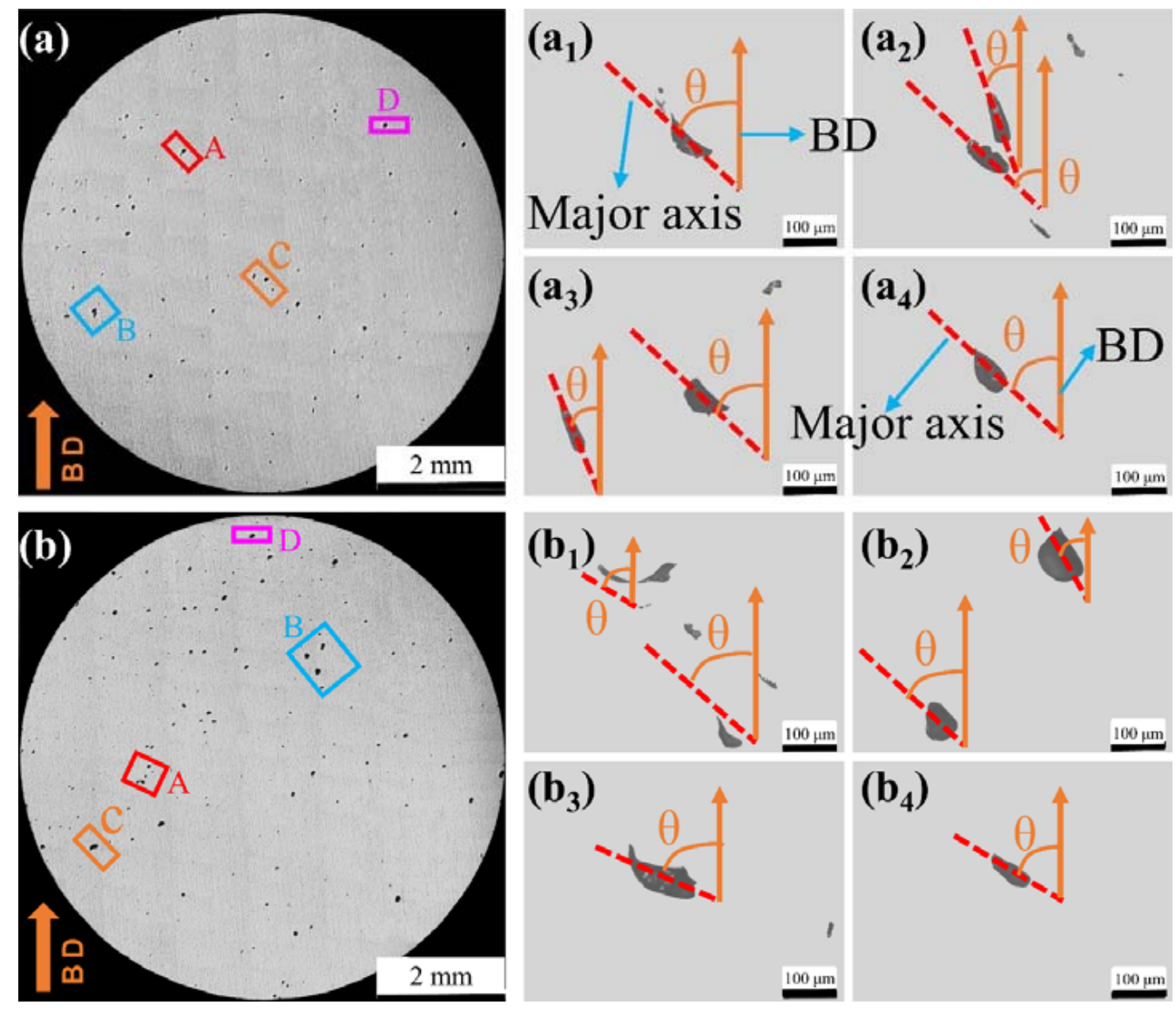

Figure 5. Porosity distribution and its morphology in longitudinal direction (parallel to build direction, BD) of TA15 specimen No. 1 (a) and No. 4 (b). (a1-a4,b1-b4) are enlarged bilaterally symmetric views of A, B, C and D in (a) and (b), respectively. 

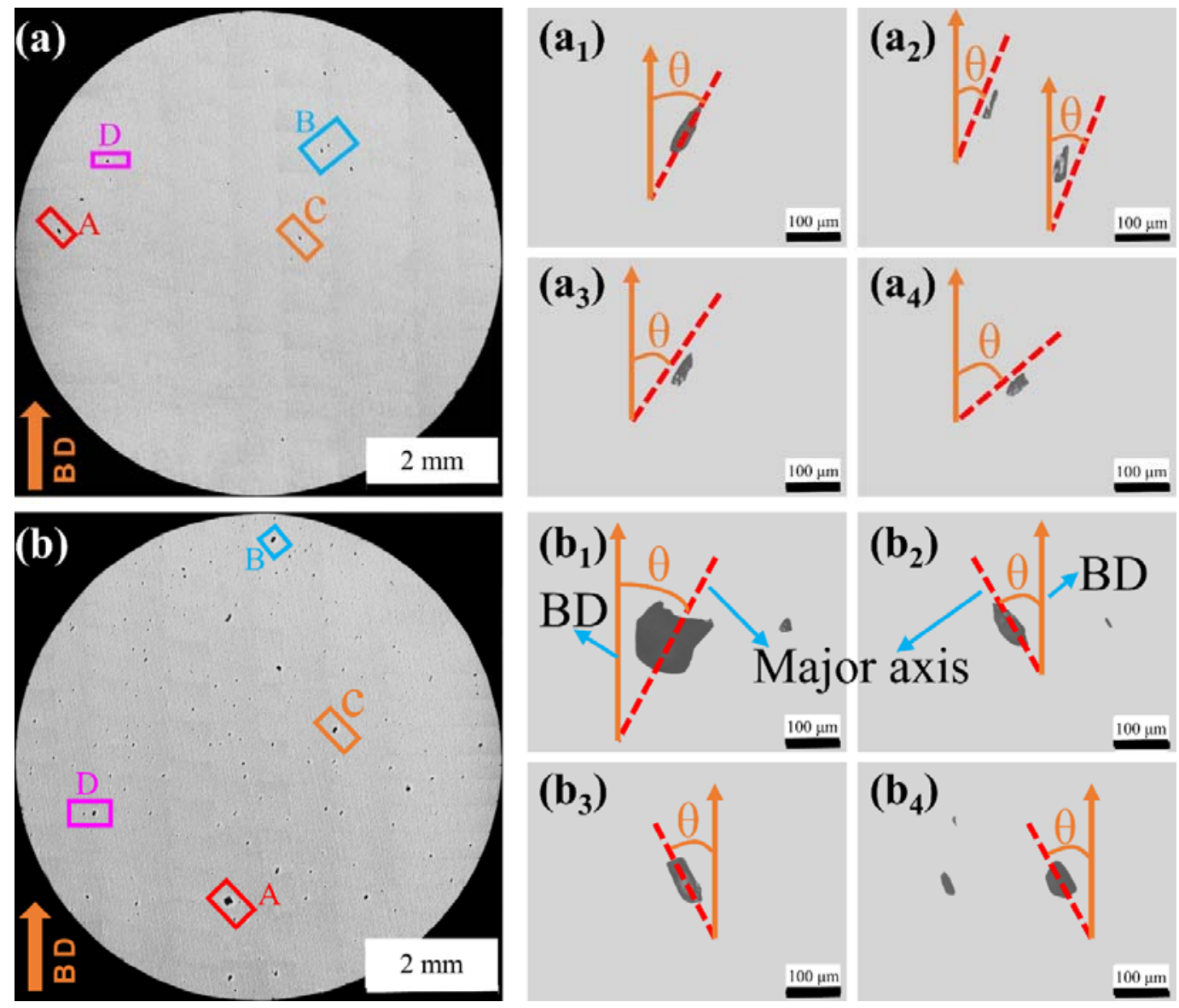

Figure 6. Porosity distribution and its morphology in longitudinal direction (parallel to build direction, BD) of TA15 specimen No. 7 (a) and No. 10 (b). (a1-a4,b1-b4) are enlarged bilaterally symmetric views of A, B, C and D in (a) and (b), respectively.

Figure 7 shows the characterization and evaluation of pores in longitudinal direction of ten TA15 specimens. Figure 7a shows the pores area fraction of ten TA15 specimens. The area fraction of pores is defined as the ratio of the pixels of the porosity to the total pixels of one micrograph. TA15 specimen No. 1 to No. 10 were successively cut from the bottom to the top of one same TA15 specimen with a height of $100 \mathrm{~mm}$, thus, Figure 7 can represent the relationship between porosity and build height. The maximum porosity area fraction is measured as $0.94 \%$ while the minimum porosity area fraction is measured as $0.28 \%$. In other words, the corresponding maximum relative density is $99.72 \%$ while the minimum relative density is $99.06 \%$. Additionally, the average porosity area fraction is measured as $0.58 \%$, corresponding to a relative density of $99.42 \%$. Guschlbauer [53] has reported 99.95\% pure copper produced by electron beam melting. Zhai et al. [27] has reported $99.85 \%$ Ti-6Al-4V for the A2 batch specimens built by electron beam melting. Galarraga et al. [36] has discovered $99.75 \%$ Ti-6Al-4V samples fabricated by electron beam melting. These results show that EBM technology can be used to produce nearly fully dense metal parts. Figure $7 \mathrm{~b}$ shows the maximum size of porosity in longitudinal direction of ten TA15 specimens. The length of major axis of pores varies from $80 \mu \mathrm{m}$ to $170 \mu \mathrm{m}$ while that of minor axis varies from $20 \mu \mathrm{m}$ to $110 \mu \mathrm{m}$. Figure $7 \mathrm{c}$ shows the measured porosity area in $\mu \mathrm{m}^{2}$. The porosity area varies from 2000 to $14,000 \mu \mathrm{m}^{2}$. Figure $7 \mathrm{~d}$ shows the aspect ratio of pores with the largest size of each TA15 specimen. Aspect ratio is defined as the ratio between the length of major axis and minor axis. When the aspect ratio is close to 1 , it means that these pores are spherical or near spherical. Unfortunately, the measured aspect ratio of these pores are greater than 1 , sometimes even as high as 3 , indicating that these pores are linear or ellipsoidal in shape. 
(a)

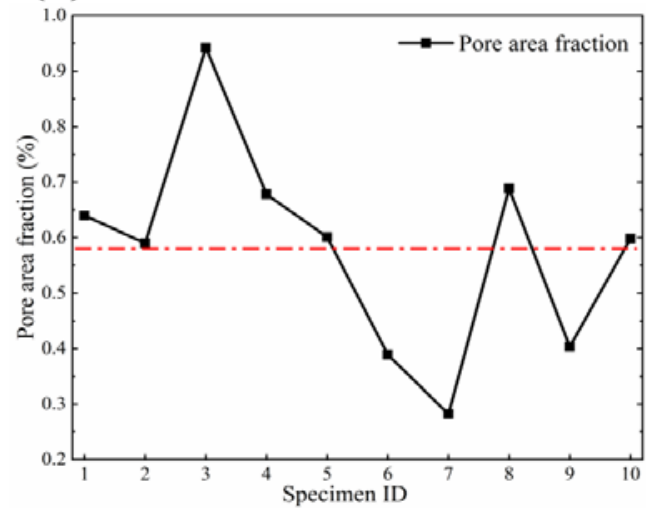

(c)

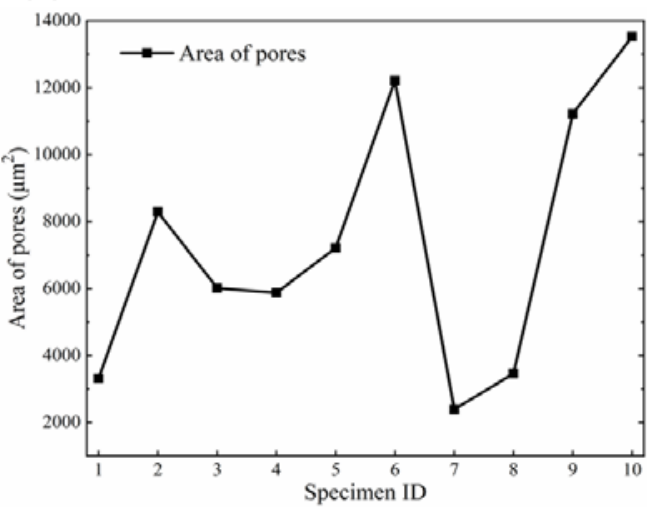

(b)

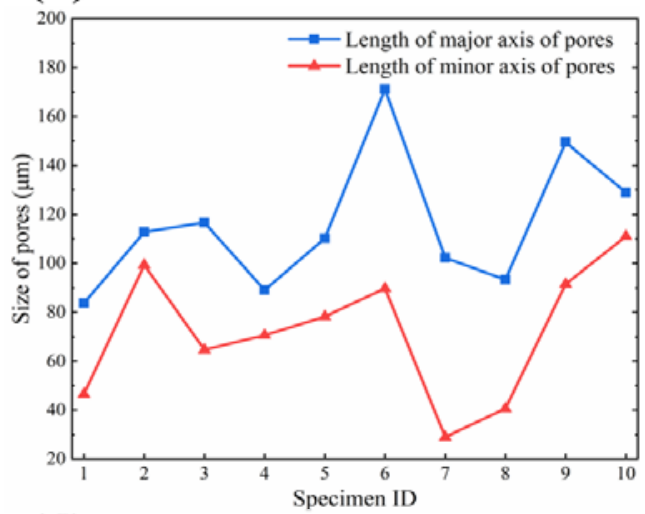

(d)

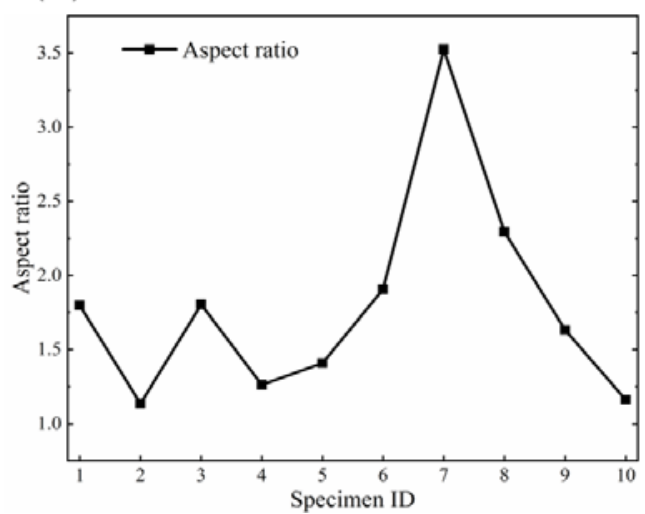

Figure 7. The evaluation of pores in longitudinal direction (parallel to build direction) of TA15 specimen: (a) pore area fraction; (b) length of major and minor axis of pores with the largest size; (c) area of pores with the largest size and (d) aspect ratio of pores with the largest size.

It can be seen from Figure 7 that when increasing build height, area fraction, size and aspect ratio of pores show no obvious trend. The comprehensive analysis results of Figures 5-7 show that there are substantial differences in relative density, pore size and distribution of samples extracted from different build heights. When comparing the relative density of different samples, it is necessary to explain the different locations of samples.

Figure 8 shows the microstructures and scanning layers in longitudinal direction of TA15 specimen No. 1, No. 4, No. 7 and No. 10. Columnar grain structure was found to orient approximately along the build direction and epitaxially grow across multiple powder layers, this phenomenon was also reported by numerous investigations $[23,27,35,36,54]$. The morphology of columnar grains is irregular and there are huge difficulties in accurately distinguish their boundaries, so it is difficult to quantitatively evaluate the size of columnar grains. However, the morphology, distribution and quantity of these columnar grains are not identical for these four specimens. Since these specimens were cut from different build heights, a conclusion can be drawn that build height has an important effect on the microstructures of TA15 specimens. High thermal gradient, heat dissipation along the build direction during the electron beam melting of TA15 titanium alloy are underlying factors contributed to the epitaxial growth of columnar grains. 

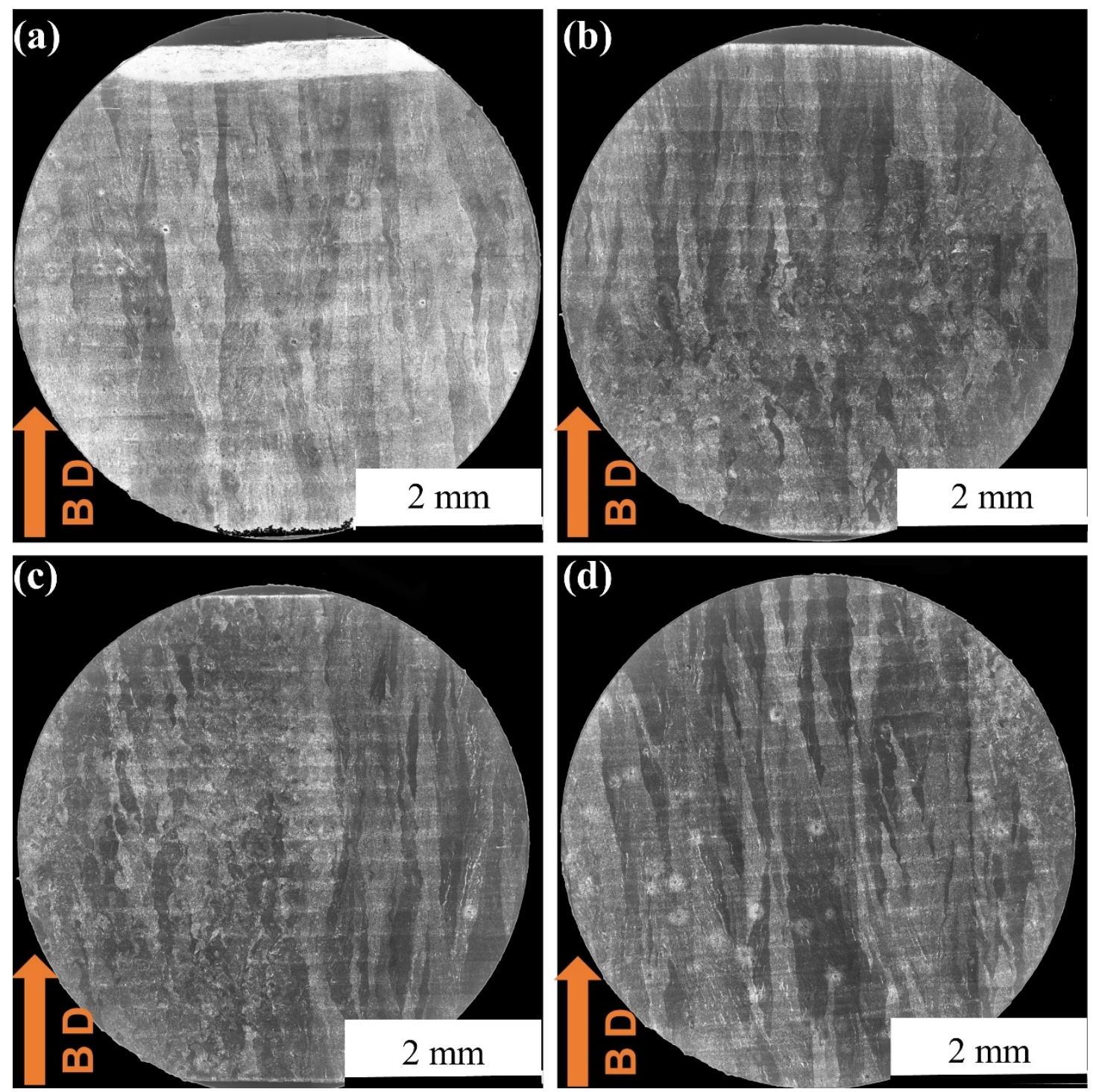

Figure 8. Microstructures and scanning layers in longitudinal direction (parallel to build direction) of TA15 specimen No. 1 (a), No. 4 (b), No. 7 (c) and No. 10 (d). The build direction is indicated by the arrow.

Figure 9 (low magnification) and Figure 10 (high magnification) show the scanning electron microscope photographs of the microstructure in longitudinal direction of TA15 specimen No. 1, No. 4, No. 7 and No. 10. Some apparently visible grain boundaries are marked by red dotted lines. It can be shown that grain boundaries are not always visibly distinguishable. Thus, it is virtually impossible to quantitatively evaluate columnar grains. However, these columnar grains are arranged along the build direction, which is in consistent with the results of optical micrographs illustrated in Figure 8. Lack of fusion defect is observed and a huge number of bulk $\alpha$ grains are also visible in Figure 10a. Bulk $\alpha$ grains and acicular $\beta$ phases are observed in Figure $10 \mathrm{~b}-\mathrm{d}$, however, much more acicular $\beta$ phases are observed in Figure $10 \mathrm{~d}$. What is more, these $\beta$ phases in Figure $10 \mathrm{~d}$ are finer and longer. The number, morphology and size of $\alpha$ phases and $\beta$ phases are different for these four specimens. Considering that they are taken from different build heights of the same part, it can make a conclusion that the extracted position has a significantly important effect on the microstructures of EBM TA15 specimens. These four samples are extracted from different build heights, so they are subjected to different thermal cycles in the forming process. The difference of thermal cycles is one of the fundamental reasons accounted for the various microstructures of these four samples. Samples at the bottom end are subjected 
to an elevated temperature for a longer time, resulting in the growth and coarsening of $\alpha$ phases and $\beta$ phases.
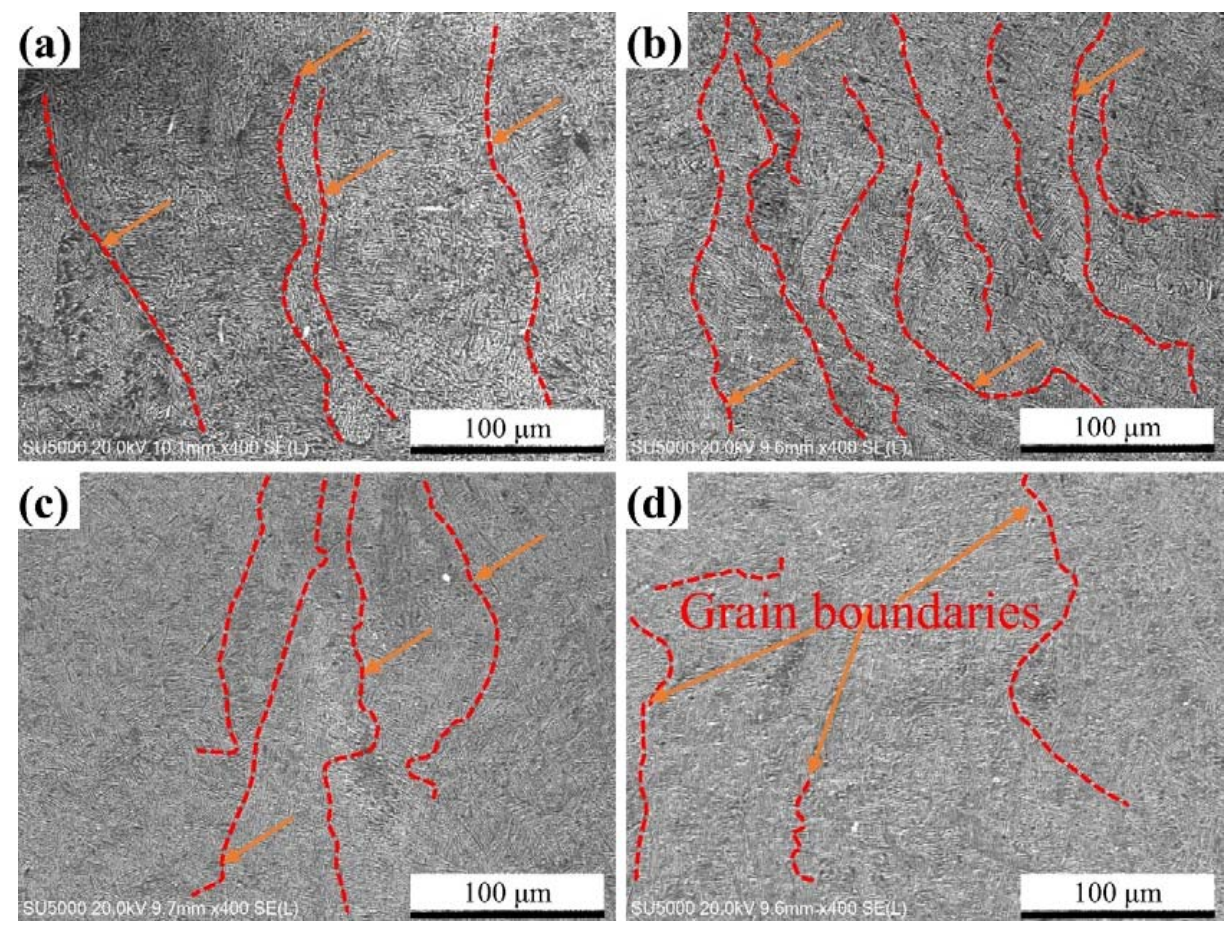

Figure 9. SEM images showing various microstructures (low magnification) in longitudinal direction (parallel to build direction) of TA15 specimen No. 1 (a), No. 4 (b), No. 7 (c) and No. 10 (d).
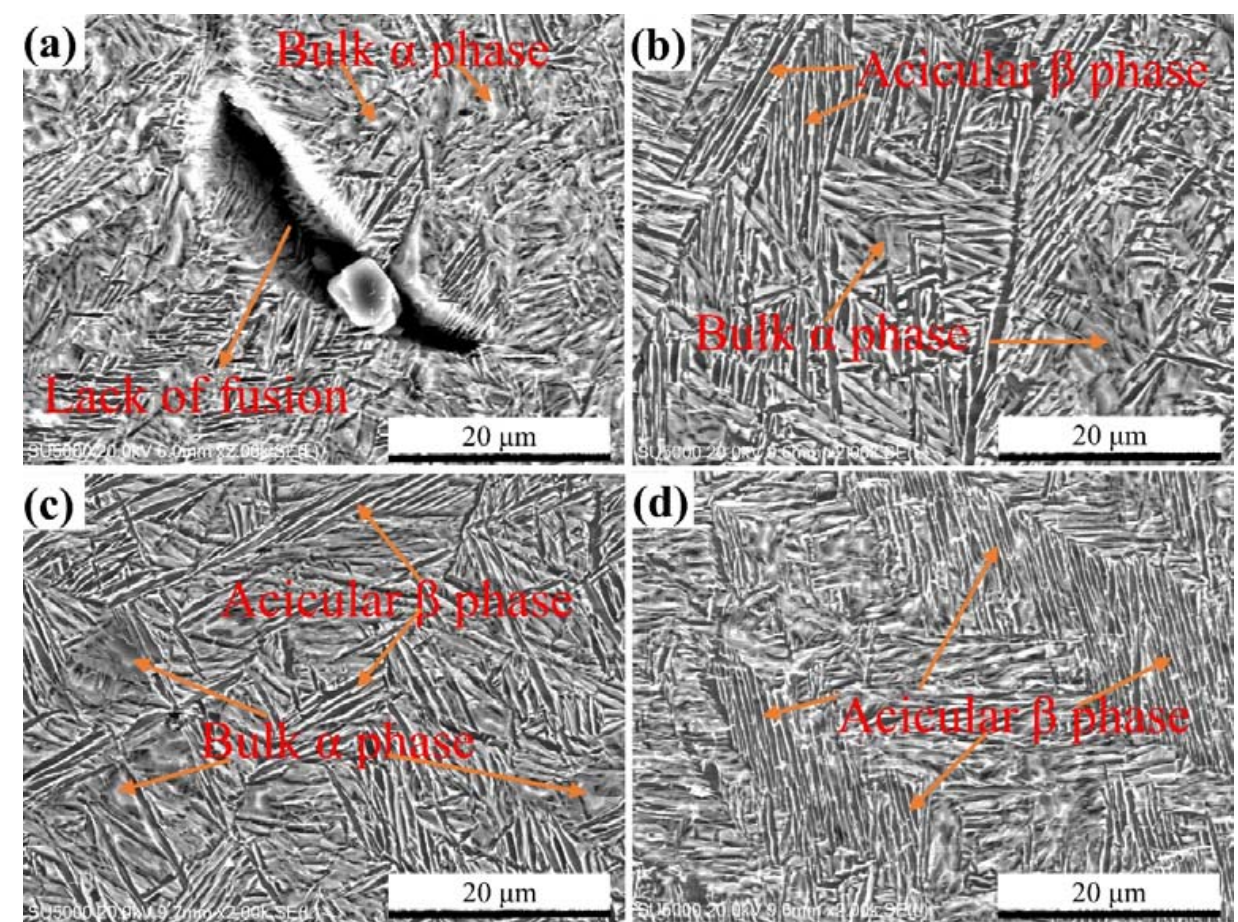

Figure 10. SEM images showing various microstructures (high magnification) in longitudinal direction (parallel to build direction) of TA15 specimen No. 1 (a), No. 4 (b), No. 7 (c) and No. 10 (d).

Figures 11 and 12 are the energy spectrum analyses showing the chemical composition variation in different positions of vertical sides from No. 1, No. 4, No. 7 and No. 10 TA15 
specimens. Figure 11 (left) and Figure 12 (left) are the positions selected for energy spectrum analysis while Figure 11 (right) and Figure 12 (right) are the corresponding energy spectrum.
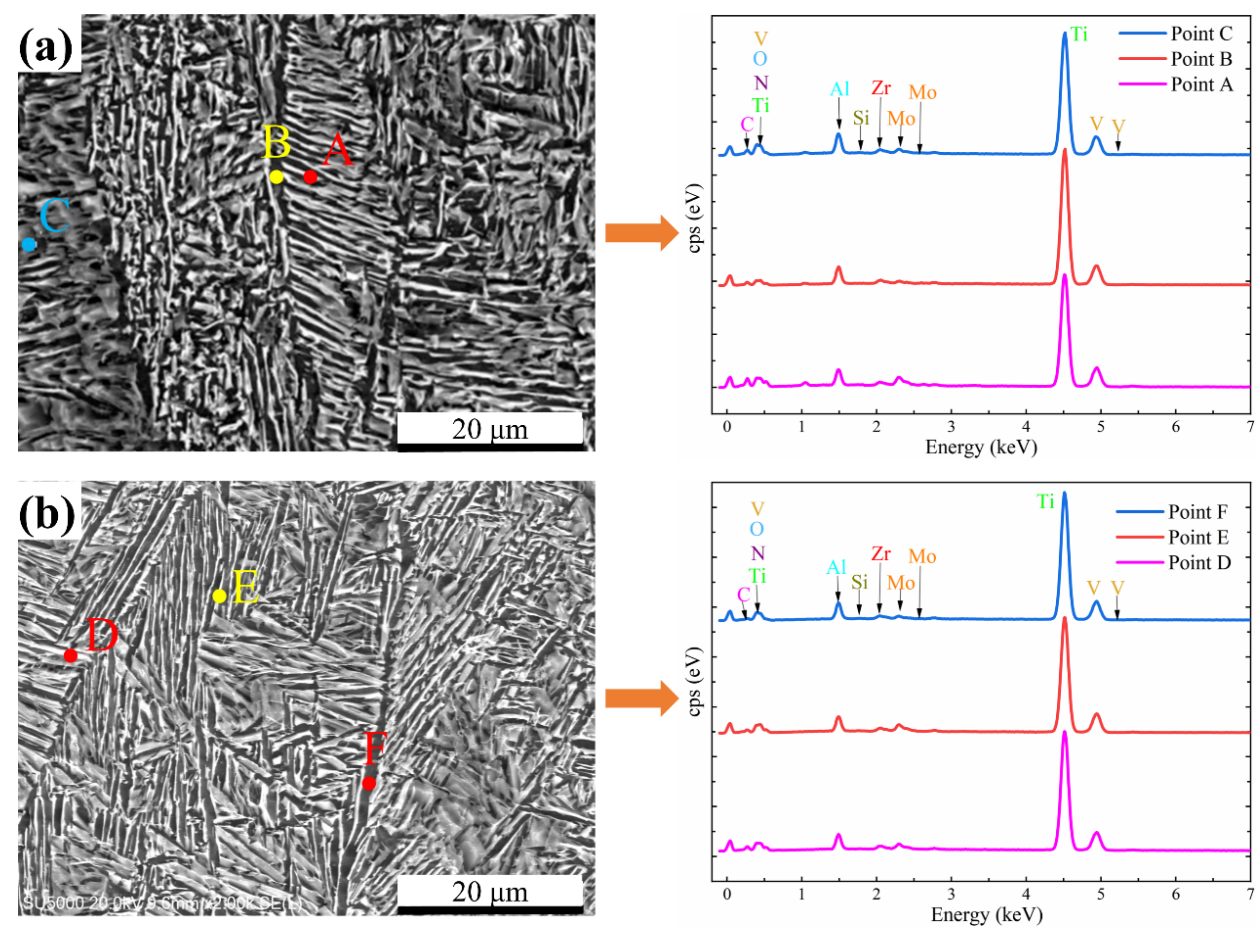

Figure 11. Energy spectrum analysis showing the chemical composition variation in $\alpha$ phase, $\beta$ phase and grain boundaries in longitudinal direction (parallel to build direction) of TA15 specimen No. 1 (a) and No. 4 (b).
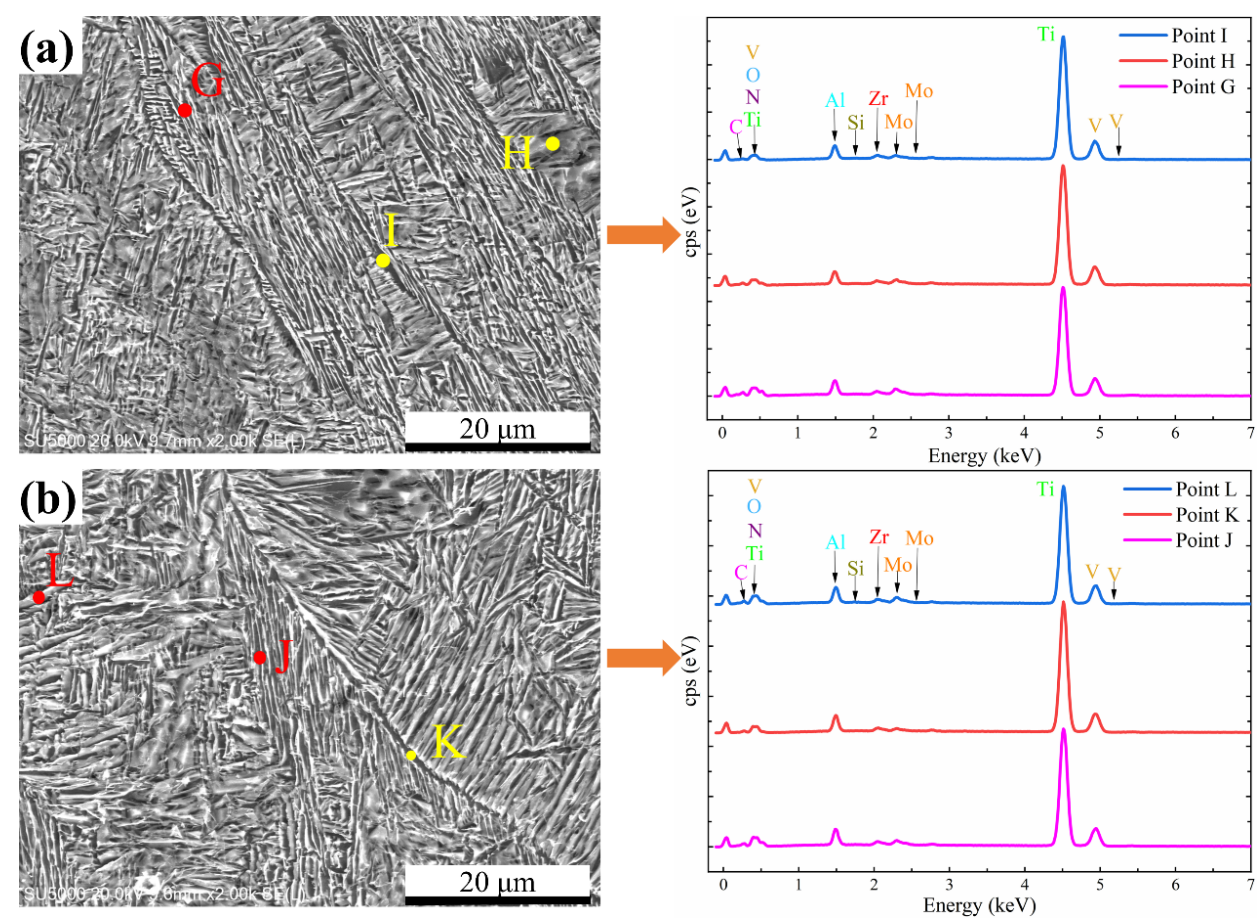

Figure 12. Energy spectrum analysis showing the chemical composition variation in $\alpha$ phase, $\beta$ phase and grain boundaries in longitudinal direction (parallel to build direction) of TA15 specimen No. 7 (a) and No. 10 (b). 
Table 3 shows the mass fraction (wt.\%) of major metal elements of different positions in longitudinal direction (parallel to build direction) of TA 15 specimen No. 1, No. 4, No. 7 and No. 10. Al element is a typical $\alpha$ stable element. Mo and V elements are typical $\beta$ stable elements while Zr element is a typical neutral element. For No. 1 and No. 4 TA15 specimens, the mass fraction of $\mathrm{Al}$ in $\alpha$ phase is noticeably higher than that in $\beta$ phase. While for No. 7 and No. 10 TA15 specimens, an opposite phenomenon is observed. The content of $\mathrm{Al}$ in $\alpha$ phase and $\beta$ phase of No. 7 and No. 10 TA15 samples is nearly the same. It is noted that the content of $\mathrm{Al}$ in grain boundary is lower than that in $\alpha$ phase but higher than that in $\beta$ phase for No. 1 and No. 4 TA15 specimens. As for No. 7 and No. 10 TA15 specimens, the content of Al in grain boundary is higher than that in both $\alpha$ phase and $\beta$ phase. This phenomenon demonstrates that Al concentration is related to the build height. The mass fraction of Mo and V elements in $\alpha$ phase is noticeably lower than that in $\beta$ phase for these four TA15 specimens. However, the mass fraction of Mo and V elements in grain boundaries is lower than that in both $\alpha$ phase and $\beta$ phase. The mass fraction of $\mathrm{Zr}$ element is almost the same in $\alpha$ phase, $\beta$ phase and grain boundaries for these four TA15 specimens. This phenomenon indicates that the Mo, V, Zr concentration may not be related to the build height.

Table 3. The mass fraction (wt.\%) of major metal elements of different positions in longitudinal direction (parallel to build direction) of TA 15 specimen No. 1, No. 4, No. 7 and No. 10.

\begin{tabular}{cccccc}
\hline Sample ID & Position & Al & V & Zr & Mo \\
\hline Powders & & 6.72 & 2.3 & 2.26 & 1.84 \\
\hline \multirow{3}{*}{ No. 1 } & Point A & 3.83 & 3.04 & 1.40 & 4.85 \\
\cline { 2 - 6 } & Point B & 4.78 & 1.75 & 1.86 & 1.49 \\
\cline { 2 - 6 } & Point C & 5.49 & 2.25 & 1.86 & 2.80 \\
\hline \multirow{3}{*}{ No. 4 } & Point D & 4.41 & 2.53 & 1.98 & 3.37 \\
\cline { 2 - 6 } & Point E & 4.60 & 3.55 & 2.00 & 4.55 \\
\cline { 2 - 6 } No. 7 & Point F & 5.17 & 2.05 & 1.83 & 1.89 \\
\cline { 2 - 6 } & Point G & 4.30 & 2.68 & 1.97 & 3.71 \\
\hline \multirow{nyyyyy}{*}{ No. 10 } & Point H & 4.07 & 2.54 & 1.74 & 2.76 \\
& Point I & 4.42 & 2.32 & 2.10 & 2.11 \\
\cline { 2 - 5 } & Point J & 4.77 & 2.92 & 2.09 & 3.60 \\
\hline & Point K & 5.09 & 2.13 & 2.06 & 1.73 \\
\hline
\end{tabular}

Figure 13 shows the EDS maps of major metal elements in longitudinal direction of TA15 specimen No. 1. The extracted position of sample No. 1 is close to the stainless-steel base plate. During the forming process, the major metal elements in TA15 titanium alloy may diffuse to stainless substrate, resulting in the uneven distribution of metal elements. Therefore, sample No. 1 is selected for area scan analysis. It can be seen from Figure 13 that the major metal elements are evenly distributed on the whole scanning area. No element segregation or enrichment is observed. When casting technology is used to produce metal parts, it is easy to form segregation zone with rich elements in the center of these parts. Since no element enrichment or segregation was observed during the elctron beam melting of TA15 titanium alloy, this suggests that EBM technology can be used to form TA15 titanium alloy parts. 

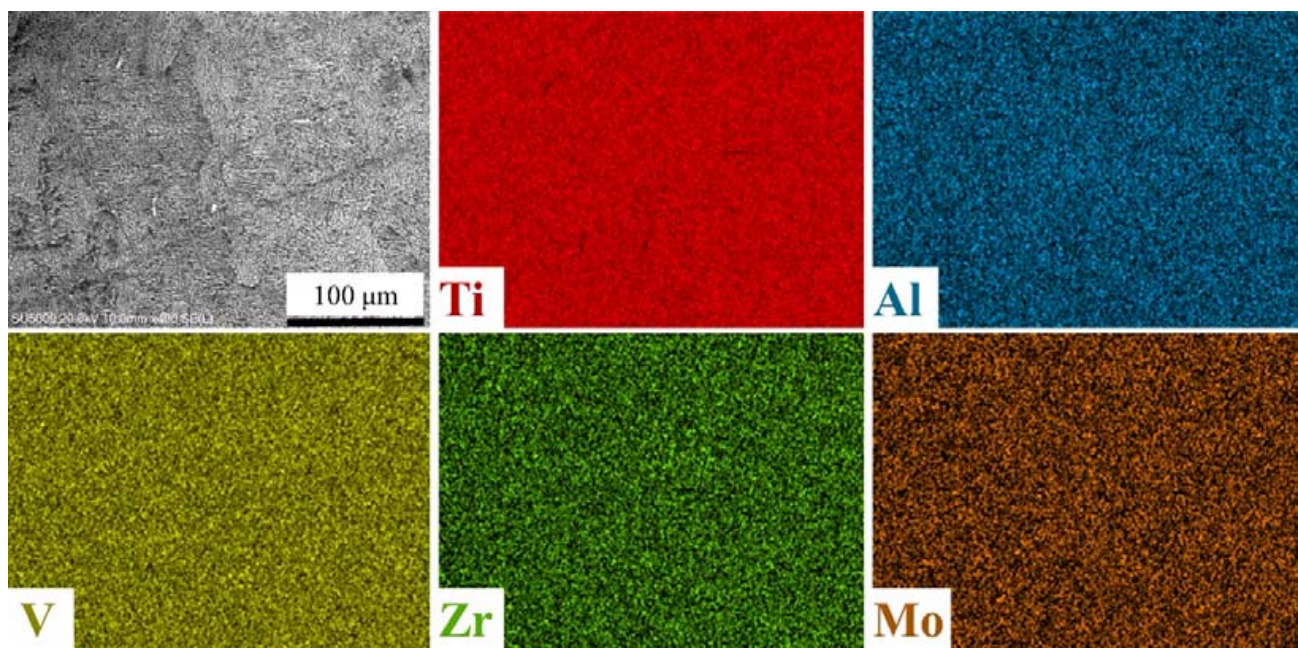

Figure 13. EDS maps showing the major metal elements distribution in longitudinal direction (parallel to build direction) of EBM TA15 specimen No. 1.

Figure 14 shows the optical micrographs of microstructures in longitudinal direction (parallel to build direction) of TA15 specimen No. 1 (a), No. 3 (b), No. 5 (c), No. 7 (d), No. 9 (e) and No. 10 (f).
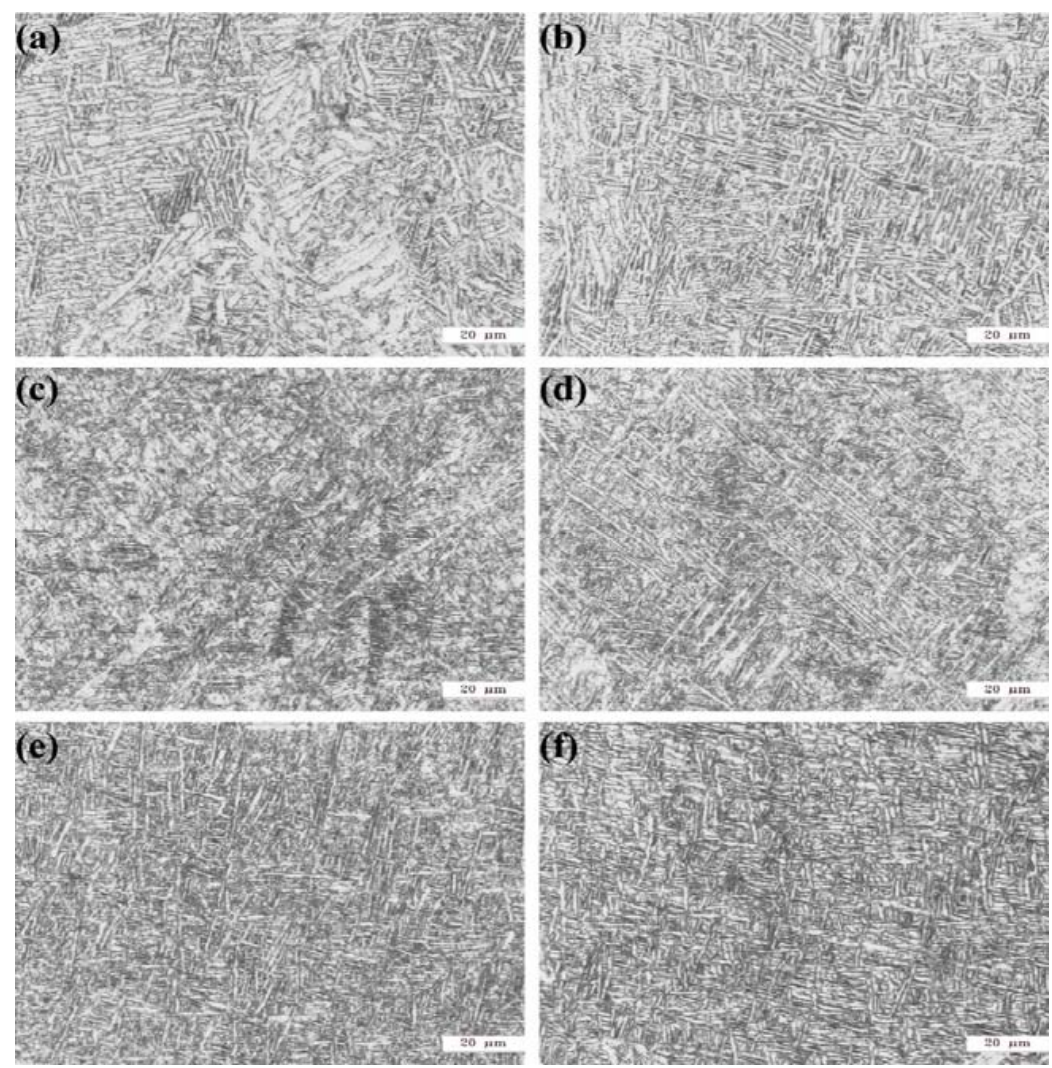

Figure 14. Optical micrographs showing different microstructures in longitudinal direction (parallel to build direction) of TA15 specimen No. 1 (a), No. 3 (b), No. 5 (c), No. 7 (d), No. 9 (e) and No. 10 (f).

It can be seen from Figure 14 that the size of $\alpha$ grains of TA15 specimen No. 1 is the largest of these six specimens. Notice that these metallographic samples are extracted from different build heights and that TA15 specimen No. 1 is cut from the bottom end, this indicates that the microstructures of specimen cut from the bottom end of one part are coarser. The morphology and distribution of $\alpha$ phases within these six samples are 
different from each other. A huge number of strip-like $\alpha$ grains are observed within TA15 specimen No. 1 and No. 3. Massive and acicular $\alpha$ grains are visible within TA15 specimen No. 5 and No. 7. Rodlike and needle-like $\alpha$ grains are found to exsit within TA15 specimen No. 9 and No. 10. During EBM process, cooling rate has a significant effect on the phase transformation behavior and microstructure size. The repeated heating and cooling process in the electron beam melting of TA15 materials will affect the microstructures formed later. TA15 specimen No. 1 is kept at an elevated temperature longer than other parts, this temperature is below martensitic transformation temperature, resulting in a coarsening effect of $\alpha$ phases. The growth of $\alpha$ phases makes their size larger than that of other parts. Specimen No. 10 is at the top, the dwell time at elevated temperature is too short for the growth of $\alpha$ grains. As a result, the size of $\alpha$ grains is smaller compared to that in the bottom end.

\subsection{Microstructure in Transversal Direction of TA15 Specimen}

Figures 15 and 16 show the porosity distribution in transversal direction (perpendicular to build direction) of TA15 specimen No. 1, No. 4, No. 7 and No. 10. The number, size and distribution of pores are obviously different for these four specimens. For TA15 specimen No. 1, hot cracks are visible in the bottom surface, as is shown in Figure 15(a1). It should be noted that this metallographic specimen is the only one with hot cracks. The formation of hot cracks is related to thermal stress. During the electron beam melting of these powders, the molten pool temperature is higher than $1600^{\circ} \mathrm{C}$, while the preheating temperature of the base plate is about $700^{\circ} \mathrm{C}$. After the electron beam leaves the molten pool, the material begins to cool off rapidly from the molten temperature and then solidifies. As the cooling time of material is very short, the thermal stress produced can not be released in time, which exceeds the strength limit of the material, so the hot cracks come into being. Increasing the preheating temperature or decreasing the scanning speed of electron beam can reduce the temperature gradient and thermal stress in the building process to a certain extent, so as to reduce or even completely avoid the formation of hot cracks.

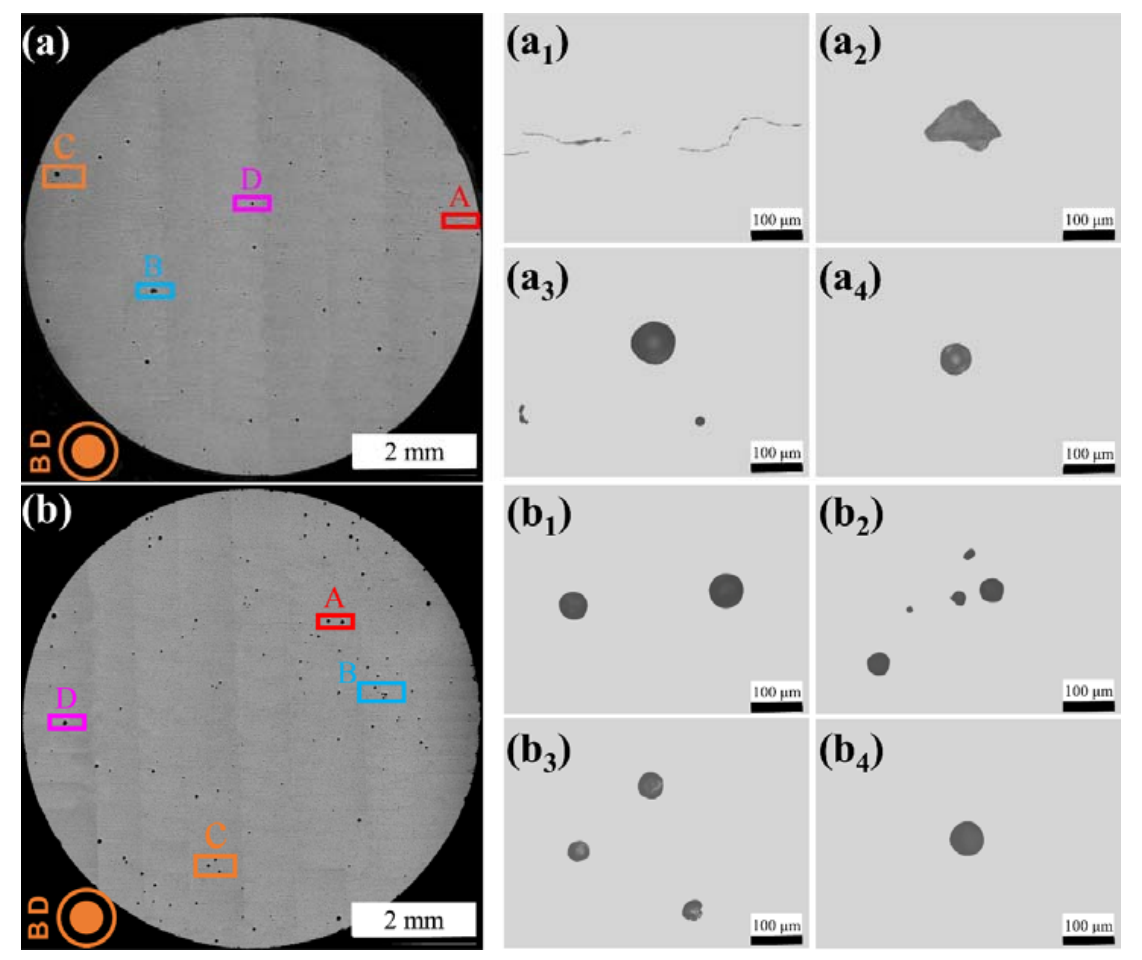

Figure 15. Pore distribution and its morphology in transversal direction (perpendicular to build direction, BD) of TA15 specimen No. 1 (a) and No. 4 (b). (a1-a4,b1-b4) are enlarged bilaterally symmetric views of A, B, C and D in (a) and (b), respectively. 

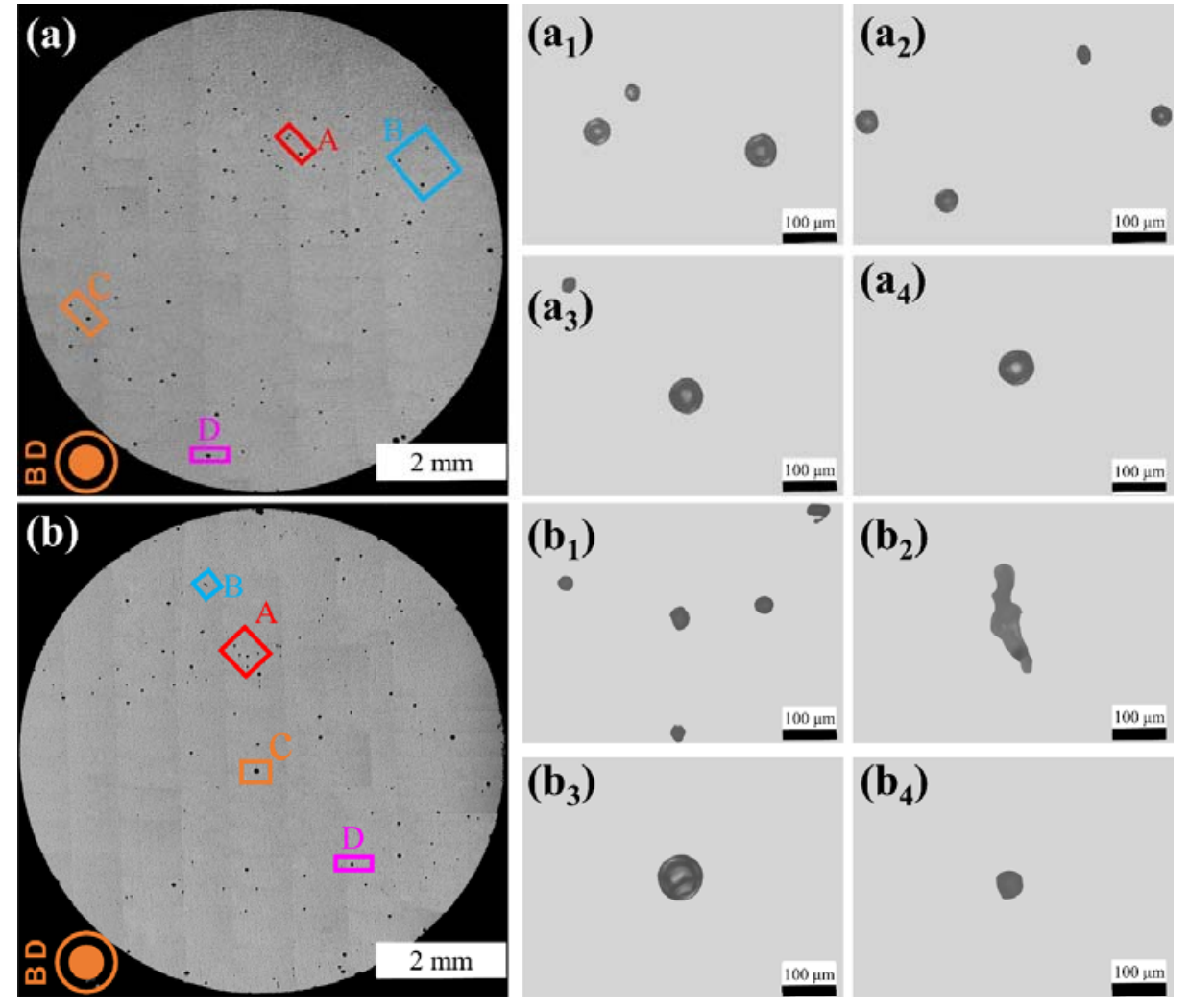

Figure 16. Pore distribution and its morphology in transversal direction (perpendicular to build direction, BD) of TA15 specimen No. 7 (a) and No. 10 (b). (a1-a4,b1-b4) are enlarged bilaterally symmetric views of A, B, C and D in (a) and (b), respectively.

In addition to hot cracks, build defects can be classified into two categories, spherical defects and linear defects. Obviously, the morphology of most defects is spherical. This kind of defects is very common in electron beam melting process. Such spherical defects are usually regarded as gas pores. Three possible reasons are accounted for the formation of gas pores. First of all, these gas pores may result from the entrapped gas inner the metal powders [36]; Secondly, there may exist residual gases in the gaps among metal powder particles, which are not able to escape from molten pool in time during the melting process. Last but not least, plasma gases are produced because of the vaporization of low melting point metals during the melting process.

Figure 17 shows the characterization and evaluation of pores in transversal direction (perpendicular to build direction) of ten TA15 specimens. TA15 specimen No. 1 to No. 10 were successively cut from the bottom to the top of one same TA15 specimen with a height of $100 \mathrm{~mm}$, thus, Figure 17 can represent the relationship between porosity and build height.

Figure 17a is the measured porosity area fraction. The maximum porosity area fraction is measured as $0.72 \%$ while the minimum porosity area fraction is measured as $0.36 \%$. In other words, the corresponding maximum relative density is $99.64 \%$ while the minimum relative density is $99.28 \%$. Additionally, the average porosity area fraction is measured as $0.5 \%$, corresponding to a relative density of $99.5 \%$. Figure $17 \mathrm{~b}$ is the length of major and minor axis of the pores with the largest size for each TA15 specimen. Surpringly, almost all of these pores are spherical or nearly spherical, thus, the length of major and minor axis is approximately equal to each other. The measured length of major axis varies from $80 \mu \mathrm{m}$ to $120 \mu \mathrm{m}$. Figure 17c shows the measured porosity area and its value varied from 3000 to $10,000 \mu^{2}$. Figure $17 \mathrm{~d}$ shows the aspect ratio of the largest pore of each TA15 specimen. For TA15 specimen No. 1 to No. 9, the aspect ratio of pores is close to 1, indicating that these pores are spherical or nearly spherical. This type of pores is usually 
treated as gas pores. Gas pores were reported by numerous investigations $[23,27,36]$ and entrapped gas within powders were attributed to the formation of gas pores when gas atomization process was used to produce precursor powders. While for TA15 specimen No. 10, a huge non-spherical pore is observed and the rapid cooling of these layers in the top end may account for the formation of this defect.

(a)

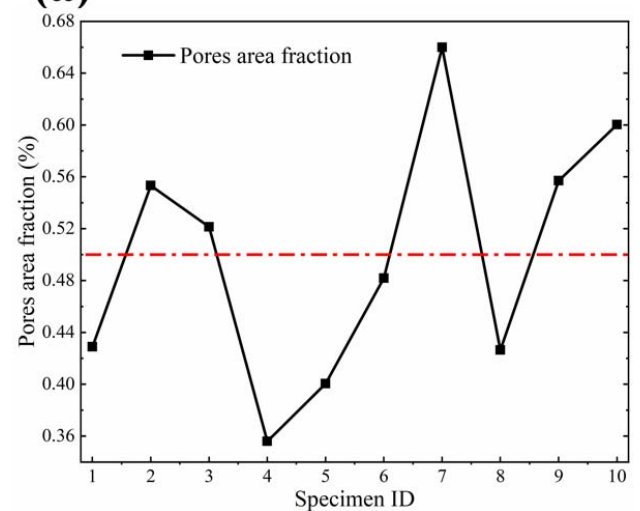

(c)

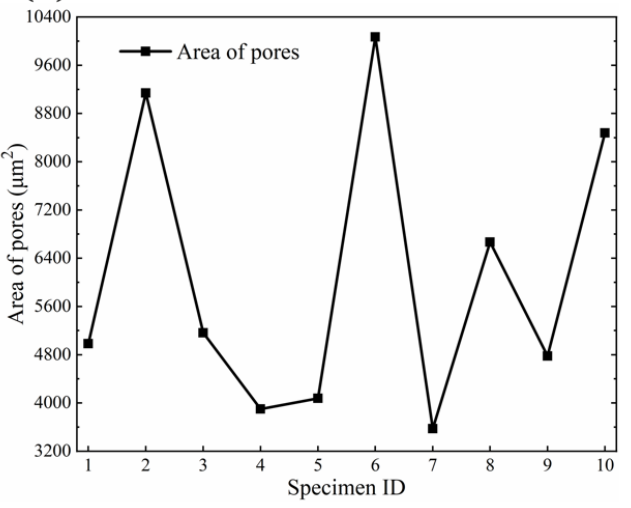

(b)

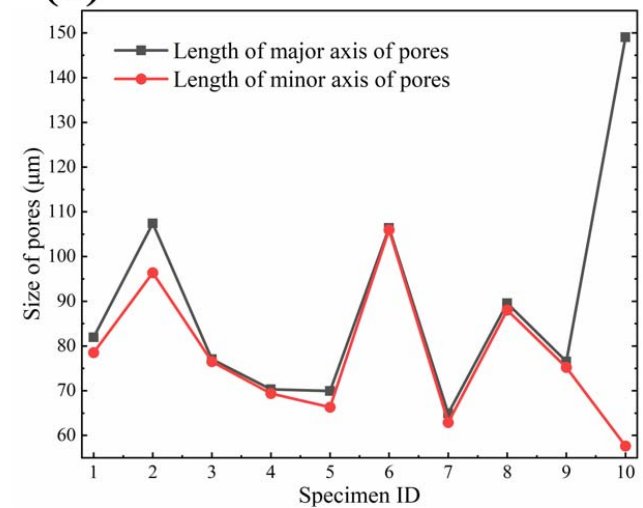

(d)

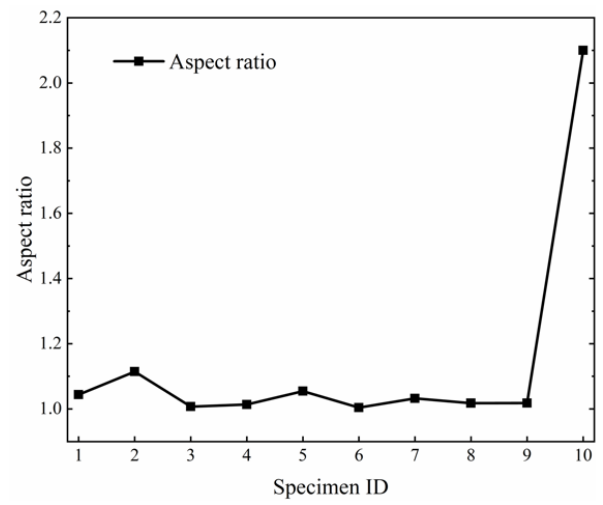

Figure 17. The evaluation of pores in transversal direction (perpendicular to build direction) of TA15 specimen: (a) porosity area fraction; (b) length of major and minor axis of pores with the largest size; (c) area of pores with the largest size and (d) aspect ratio of pores with the largest size.

It can be seen from Figure 17 that there is no remarkable trend of pore area fraction, pore size and aspect ratio with increasing build height. The comprehensive analysis results of Figures 15-17 show that there is huge difference in relative density, pore size and distribution of samples extracted from different build heights. There is a need to provide the extraction position of samples for the comparation of the relative density of different samples.

Figure 18 (low magnification) and Figure 19 (high magnification) show the SEM photographs of various microstructures in transversal direction (normal to build direction) of TA15 specimen No. 1, No. 4, No. 7 and No. 10. Some obvious grain boundaries are characterized by red dotted lines. Grain boundaries are not always visible for all specimens, thus they are only characterized in Figure 18a. Quantitative evaluation of grain size is also difficult because it is hard to distinguish grain boundaries accurately. Obviously, the grain morphology in the transversal direction shows a chessboard or reticulate-like structure, which is different from the columnar structure in longitudinal direction (Figure 9). In transversal direction, there is no specific direction for heat dissipation and the trend of grain growth in all directions is nearly the same. Thus, these grains develop into chessboard or reticulate-like structure. It can be seen from Figure 19 that some $\alpha$ phases in (a) are much coarser than in (b-d), indicatding a coarsening effect of microstructures of specimens cut from the bottom end. The size, number and morphology of $\alpha$ phases 
and $\beta$ phase are different for these specimens, which are in consistent with the results in longitudinal direction.
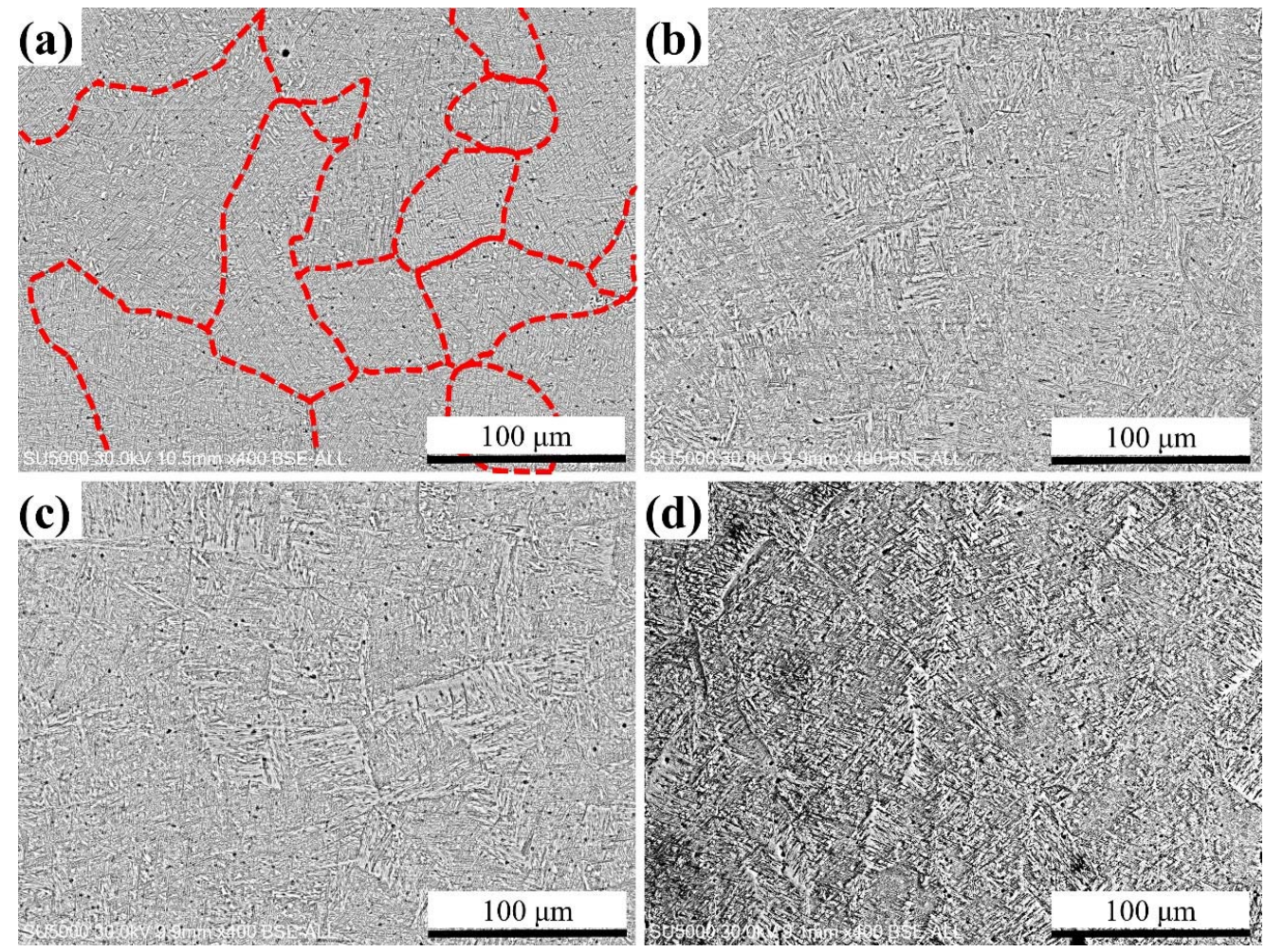

Figure 18. SEM images showing various microstructures (low magnification) in transversal direction (perpendicular to build direction) of TA15 specimen No. 1 (a), No. 4 (b), No. 7 (c) and No. 10 (d).
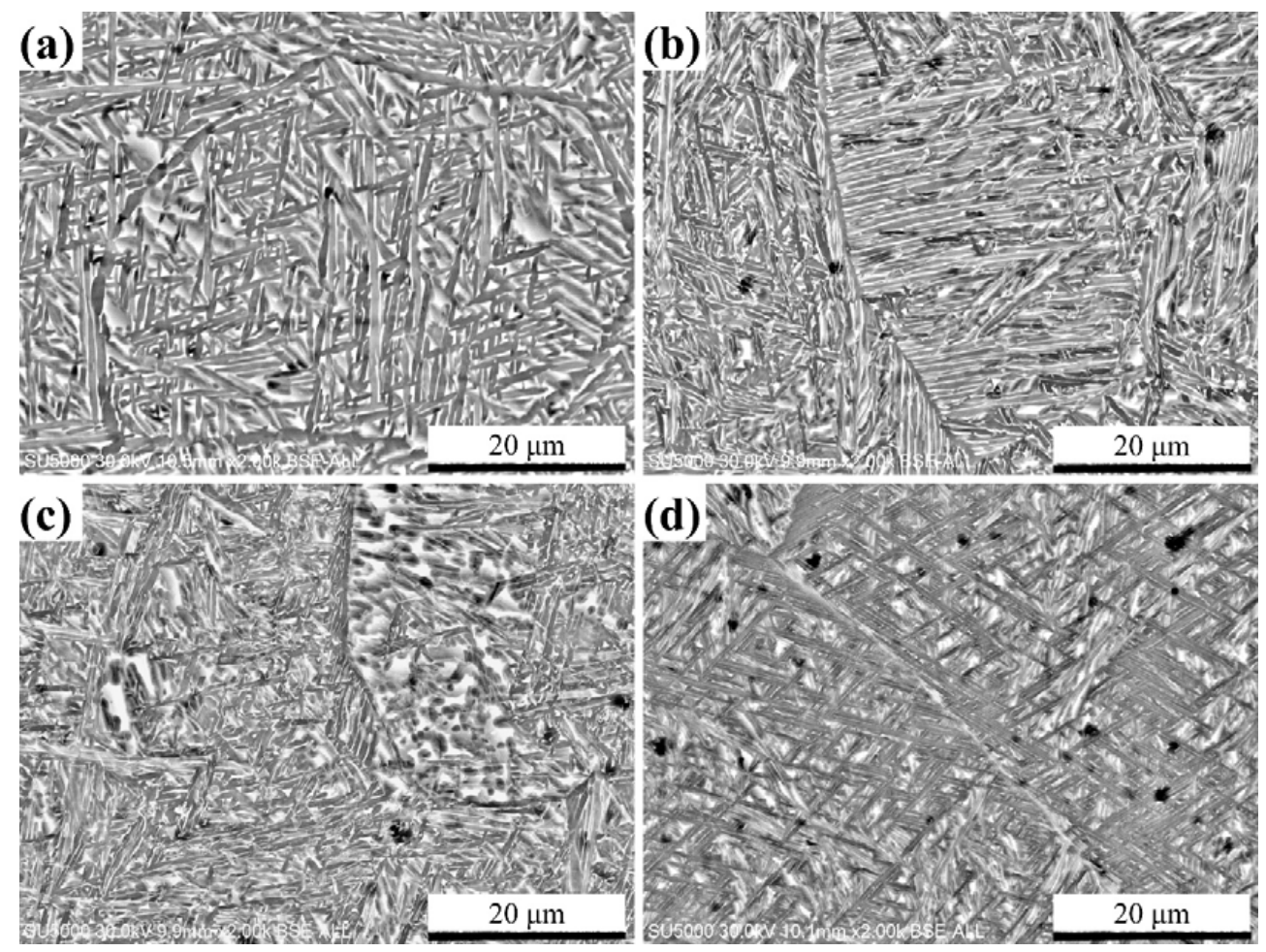

Figure 19. SEM images showing various microstructures (high magnification) in transversal direction (perpendicular to build direction) of TA15 specimen No. 1 (a), No. 4 (b), No. 7 (c) and No. 10 (d). 
Figures 20 and 21 are the energy spectrum analyses in the bottom surface of No. 1 and the top surfaces of No. 4, No. 7 and No. 10 TA15 specimens.
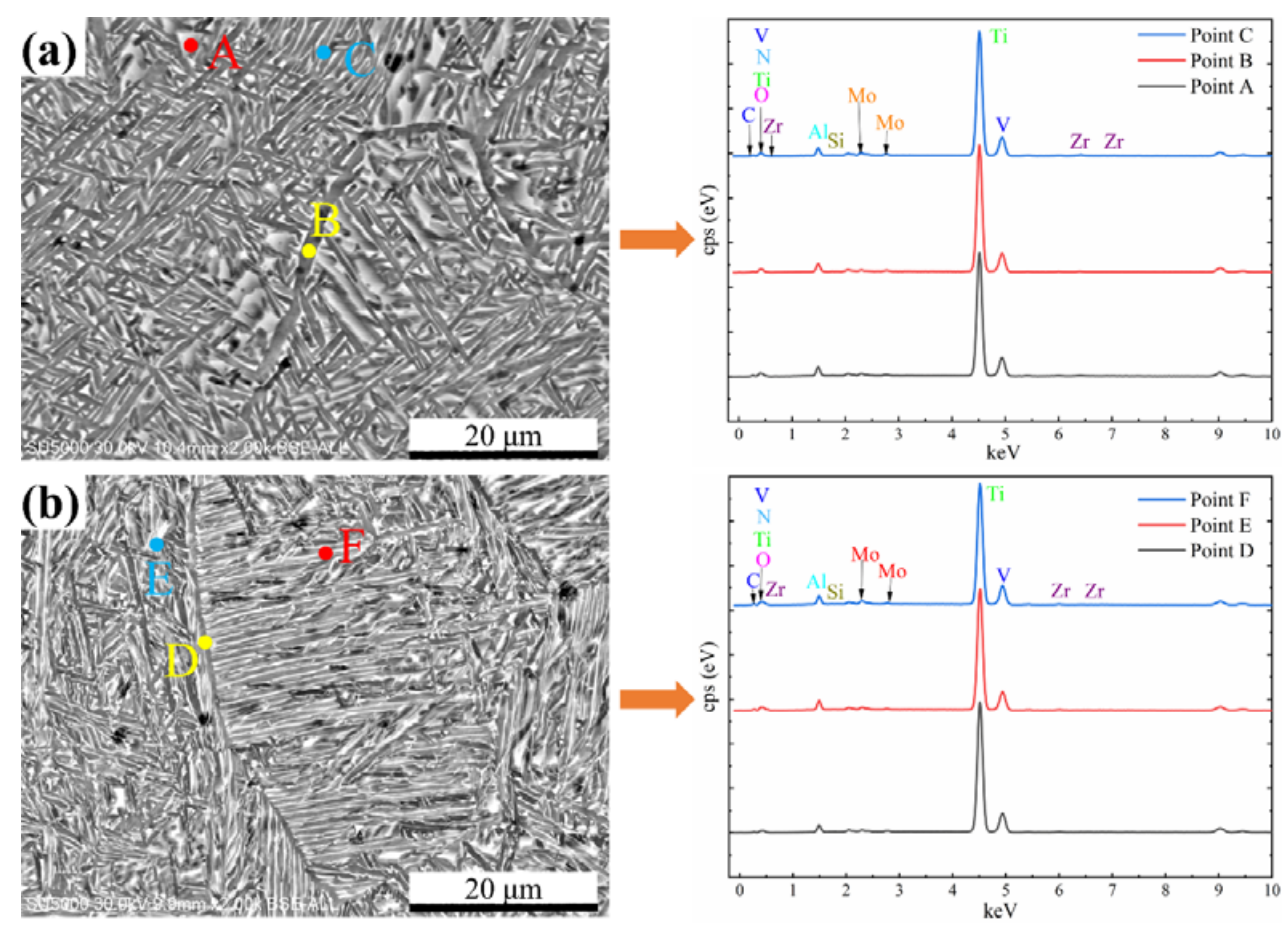

Figure 20. Energy spectrum analysis showing the chemical composition variation in $\alpha$ phase, $\beta$ phase and grain boundaries in transversal direction (perpendicular to build direction, BD) of TA15 specimen No. 1 (a) and No. 4 (b).
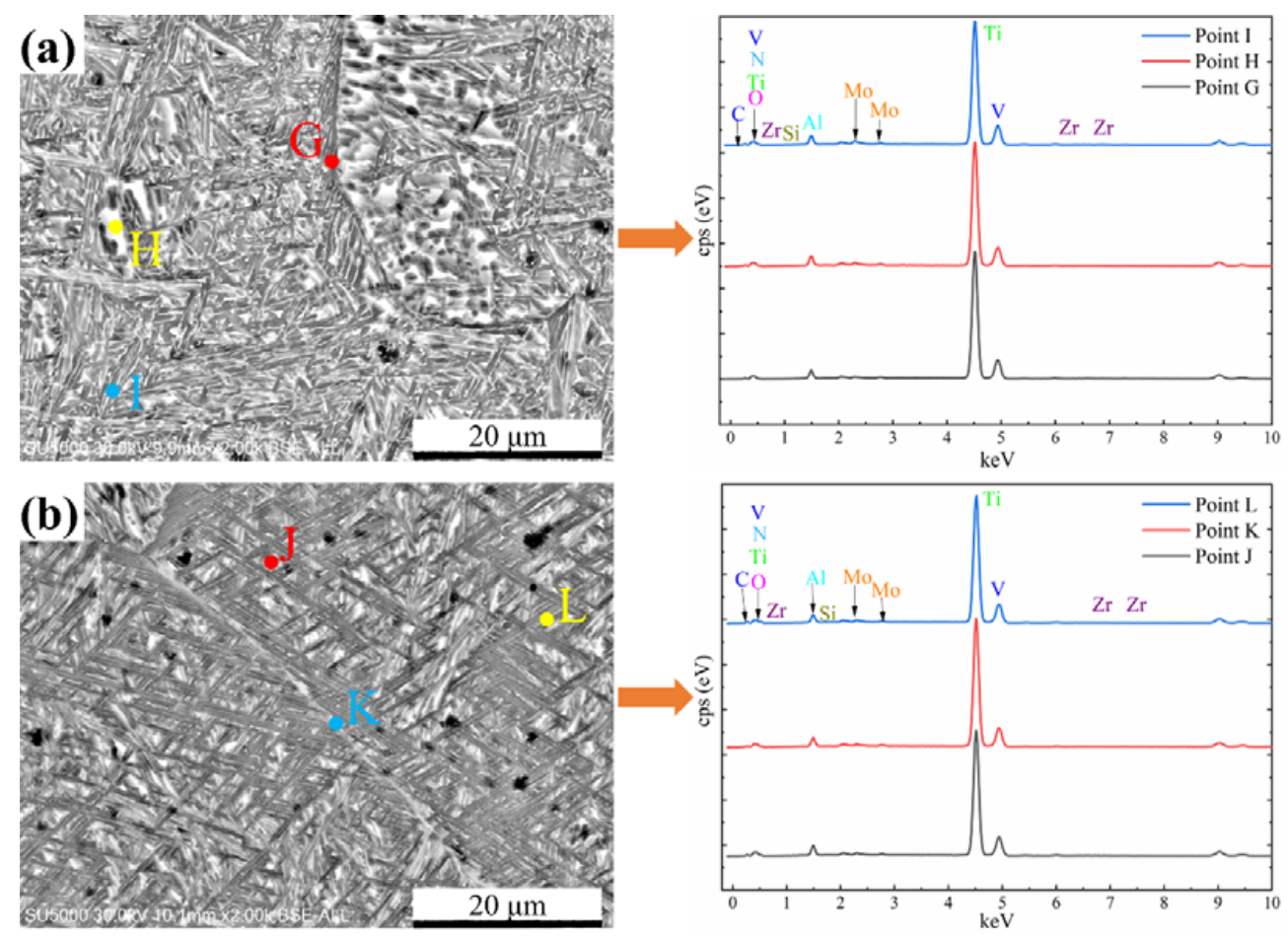

Figure 21. Energy spectrum analysis showing the chemical composition variation in in $\alpha$ phase, $\beta$ phase and grain boundaries in transversal direction (perpendicular to build direction, BD) of TA15 specimen No. 7 (a) and No. 10 (b). 
Table 4 shows the corresponding mass fraction of $\mathrm{Al}, \mathrm{Mo}, \mathrm{V}$ and $\mathrm{Zr}$ elements in different positions. Al, Mo, V and $\mathrm{Zr}$ elements are selected for chemical composition analysis. It can be seen from Figures 18 and 19 and Table 4 that the mass fraction of $\mathrm{Zr}$ element is almost the same in $\alpha$ phase, $\beta$ phase and grain boundaries. For No. 1 and No. 10 TA15 specimens, the content of $\mathrm{Al}$ in $\alpha$ phase is the highest, followed by in grain boundaries and the lowest in $\beta$ phase. For No. 4 and No. 7 TA15 specimens, the content of $\mathrm{Al}$ in $\alpha$ phase is the highest, followed by in $\beta$ phase and the lowest in grain boundaries. It is noted that the mass fraction of $\mathrm{Al}$ in the precursor powders is $6.72 \%$, the mass fraction of $\mathrm{Al}$ in different phases of the bulk sample is obviously lower than that in powders; thus, a conclusion can be made that there is remarkable vaporization of Al element during the melting process.

Table 4. The mass fraction (wt.\%) of major metal elements of different positions in transversal direction (perpendicular to build direction, BD) of TA15 specimen No. 1, No. 4, No. 7, No. 10 specimen.

\begin{tabular}{cccccc}
\hline Sample ID & Position & Al & V & Zr & Mo \\
\hline \multirow{2}{*}{ Powders } & & 6.72 & 2.3 & 2.26 & 1.84 \\
\hline \multirow{3}{*}{ No. 1 } & Point A & 3.17 & 2.72 & 1.60 & 1.72 \\
\cline { 2 - 6 } & Point B & 2.97 & 2.32 & 1.76 & 1.06 \\
\cline { 2 - 6 } & Point C & 2.70 & 2.81 & 1.66 & 2.00 \\
\hline \multirow{3}{*}{ No. 4 } & Point D & 2.53 & 2.59 & 1.88 & 1.31 \\
\cline { 2 - 6 } & Point E & 3.28 & 2.61 & 2.02 & 1.87 \\
\cline { 2 - 6 } No. 7 & Point F & 3.08 & 3.20 & 1.89 & 2.57 \\
\cline { 2 - 6 } & Point G & 2.93 & 2.62 & 1.92 & 1.15 \\
\hline \multirow{nyyyyy}{*}{ No. 10 } & Point H & 3.32 & 2.49 & 1.78 & 1.84 \\
& Point I & 3.07 & 3.00 & 2.01 & 2.41 \\
\cline { 2 - 6 } & Point J & 3.46 & 2.60 & 2.08 & 1.54 \\
\hline & Point K & 3.05 & 2.67 & 2.09 & 1.42 \\
\hline
\end{tabular}

The content of $\mathrm{Zr}$ in $\alpha$ phase, $\beta$ phase and grain boundary is almost the same, which is close to that of $\mathrm{Zr}$ in the precursor powders. This phenomenon shows that $\mathrm{Zr}$ element is a neutral element from the experimental point of view. For No. 1 and No. 4 TA15 specimens, the content of Mo and $\mathrm{V}$ in $\beta$ phase is the highest, followed by in $\alpha$ phase and the lowest in grain boundaries. For No. 7 TA15 specimen, the content of V in $\beta$ phase is the highest, followed by in grain boundaries and the lowest in $\alpha$ phase. For No. 10 TA15 specimen, the content of Mo in $\alpha$ phase is slightly higher than that in $\beta$ phase. This may be attributed to the rapidly cooling down of the molten, resulting an insufficient diffusion of elements. Nevertheless, the content of Mo in $\alpha$ phase, $\beta$ phase and grain boundary is nearly identical.

Figure 22 shows the EDS maps of major metal elements distribution in transversal direction (perpendicular to build direction) of EBM TA15 specimen No. 1. The bottom of specimen No. 1 is in direct contact with the stainless-steel start plate during the electron beam melting of TA15 titanium alloys. The chemical composition of the stainless-steel substrate is different from that of TA15 alloys, this may lead to the diffusion of metal elements. So, specimen No. 1 was selected for characterization. 

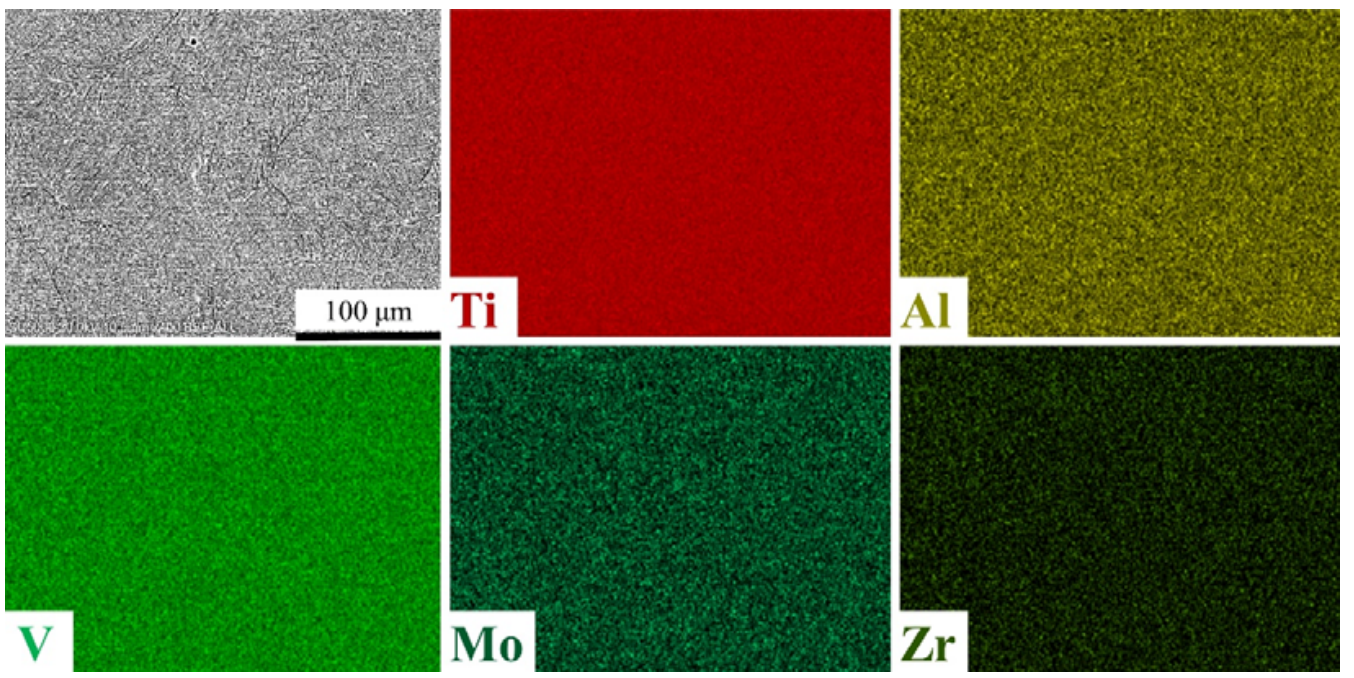

Figure 22. EDS maps showing the major metal elements distribution in transversal direction (perpendicular to build direction) of EBM TA15 specimen No. 1.

It can be seen from Figure 22 that the major metal elements are evenly distributed within the measured area, with no element segregation or enrichment. This result shows that electron beam melting technology can be used to fabricate TA15 materials.

\subsection{Microhardness in Longitudinal and Transversal Direction of EBM TA15 Specimen}

Figure 23 shows the Vickers hardness in both longitudinal and transversal direction of EBM TA15 specimens. Since these 10 specimens were taken from different build heights, Figure 23 could show the relationship between Vickers hardness and build height. Obviously, there are no evident relationship between Vickers hardness and build height both in transversal and longitudinal direction. This phenomenon is consistent with the evolving trend of Vickers hardness of EBM Ti-6Al-4V [49]. Interestingly, the Vickers hardness in the transversal direction of TA15 specimen No. 1 to No. 6 shows a decreasing trend, which is in good agreement with the existed research [46]. On the other hand, the Vickers hardness in the transversal direction of TA15 specimen No. 6 to No. 9 shows an increasing trend. Wang et al. [20,47] had reported an increasing trend of Vickers hardness of EBM Ti-6Al-4V.

(a)

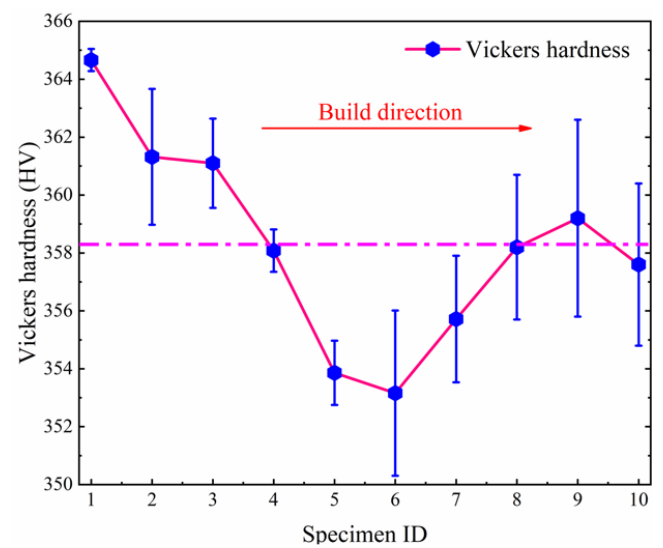

(b)

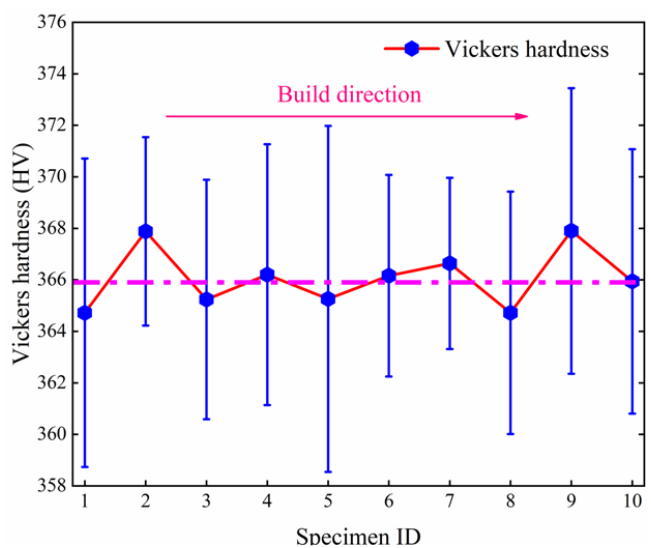

Figure 23. Variation of Vickers hardness in a transversal direction (a) and longitudinal direction (b) of TA15 specimen No. 1 to No. 10.

The average value of Vickers hardness of 10 TA15 specimens in transversal direction is about $358 \mathrm{HV}$, while that in longitudinal direction is about $366 \mathrm{HV}$. Considering the measurement accuracy and error, the Vickers hardness of these samples in two directions 
can be considered to be equal with each other. Thus, the Vickers hardness of EBM TA15 in this study is about $360 \mathrm{HV}$, which is comparable to that of EBM Ti-6Al-4V. Combined with the previous investigations and the phenomenon observed in this study, it can be concluded that there is no obvious relationship between Vickers hardness and build height. The variation of build height has little effect on the Vickers hardness of EBM TA15 specimen.

\section{Conclusions}

This study has investigated the effects of characterization direction and extracted position on the microstructure, defects and microhardness of TA15 samples fabricated by electron beam melting technology. Some conclusions can be drawn:

(1) Gas pores are visible in a transversal direction (perpendicular to build direction) and they are spherical or nearly spherical in shape, while lack of fusion defect exists in longitudinal direction (parallel to build direction) and they are ellipsoidal or linear in shape;

(2) There is no obvious change of microstructures and microhardness when increasing build heights. However, microstructure at the bottom end of one part is coarser and hot cracks are visible at this end. Thus, the characterization of microstructures of EBM materials should avoid taking metallographic specimens from the bottom of one part;

(3) Compared with the as-received powders, the content of Al within samples decreased, indicating that there is evaporation of $\mathrm{Al}$ in the forming process. The results of energy spectrum analysis show that there is no elements segregation and enrichment in the process of electron beam melting TA15 titanium alloys;

(4) The average relative density in transversal direction is slightly higher than that in a longitudinal direction. Additionally, the change range of relative density in transversal direction is smaller than that in longitudinal direction. This suggests that the transversal direction is a better choice for the evaluation of relative density.

Author Contributions: Conceptualization, H.Z.; methodology, X.S.; software, S.W.; validation, J.R.; formal analysis, J.R.; investigation, H.Z.; resources, Z.C.; data curation, J.R.; writing-original draft preparation, J.R.; writing-review and editing, H.Z., X.S.; visualization, S.W.; supervision, H.Z.; project administration, Z.C.; funding acquisition, S.W. All authors have read and agreed to the published version of the manuscript.

Funding: This study was funded by the National Key R \& D Program of China (2017YFB1103701) and Natural Science Foundation of Heilongjiang Province (LH2019E061).

Acknowledgments: Thanks to Feng-chun Jiang of Harbin Engineering University for his useful suggestions.

Conflicts of Interest: There is no direct or potential conflict of interest among all the authors of this research.

\section{References}

1. Sepe, R.; Franchitti, S.; Borrelli, R.; di Caprio, F.; Armentani, E.; Caputo, F. Correlation between real geometry and tensile mechanical behaviour for Ti6Al4V Electron Beam Melted thin specimens. Theor. Appl. Fract. Mech. 2020, 107, 102519. [CrossRef]

2. Razavi, M.; Hooreweder, B.; Berto, F. Effect of build thickness and geometry on quasi-static and fatigue behavior of Ti-6Al-4V produced by Electron Beam Melting. Addit. Manuf. 2020, 36, 101426. [CrossRef]

3. Guschlbauer, R.; Burkhardt, A.; Fu, Z.; Körner, C. Effect of the oxygen content of the powder on the selective electron beam melting of pure copper. Mater. Sci. Eng. A 2020, 779, 139106. [CrossRef]

4. Phan, M.A.L.; Fraser, D.; Gulizia, S.; Chen, Z.W. Horizontal growth direction of dendritic solidification during selective electron beam melting of a Co-based alloy. Mater. Lett. 2018, 228, 242-245. [CrossRef]

5. Wang, X.; Chou, K. Effect of support structures on Ti-6Al-4V overhang parts fabricated by powder bed fusion electron beam additive manufacturing. J. Mater. Process. Technol. 2018, 257, 65-78. [CrossRef]

6. Chauvet, E.; Tassin, C.; Blandin, J.-J.; Dendievel, R.; Martin, G. Producing Ni-base superalloys single crystal by selective electron beam melting. Scr. Mater. 2018, 152, 15-19. [CrossRef]

7. Yue, H.; Peng, H.; Li, R.; Su, Y.; Zhao, Y.; Qi, K.; Chen, Y. Selective Electron Beam Melting of TiAl Alloy: Metallurgical Defects, Tensile Property, and Determination of Process Window. Adv. Eng. Mater. 2020, 22, 2000194. [CrossRef] 
8. Murr, L.E.; Esquivel, E.V.; Quinones, S.A.; Gaytan, S.M.; Lopez, M.I.; Martinez, E.Y.; Medina, F.; Hernandez, D.H.; Martinez, E.; Martinez, J.L.; et al. Microstructures and mechanical properties of electron beam-rapid manufactured Ti-6Al-4V biomedical prototypes compared to wrought Ti-6Al-4V. Mater. Charact. 2009, 60, 96-105. [CrossRef]

9. Murr, L.E.; Quinones, S.A.; Gaytan, S.M.; Lopez, M.I.; Rodela, A.; Martinez, E.Y.; Hernandez, D.H.; Martinez, E.; Medina, F.; Wicker, R.B. Microstructure and mechanical behavior of Ti-6Al-4V produced by rapid-layer manufacturing, for biomedical applications. J. Mech. Behav. Biomed. Mater. 2009, 2, 20-32. [CrossRef] [PubMed]

10. Tan, X.; Kok, Y.; Toh, W.Q.; Tan, Y.J.; Descoins, M.; Mangelinck, D.; Tor, S.B.; Leong, K.F.; Chua, C.K. Revealing martensitic transformation and alpha/beta interface evolution in electron beam melting three-dimensional-printed Ti-6Al-4V. Sci. Rep. 2016, $6,1-10$.

11. Lu, S.-L.; Qian, M.; Tang, H.P.; Yan, M.; Wang, J.; St John, D.H. Massive transformation in Ti-6Al-4V additively manufactured by selective electron beam melting. Acta Mater. 2016, 104, 303-311. [CrossRef]

12. Zhang, Y.; Chen, Z.; Qu, S.; Feng, A.; Mi, G.; Shen, J.; Huang, X.; Chen, D. Multiple $\alpha$ sub-variants and anisotropic mechanical properties of an additively-manufactured Ti-6Al-4V alloy. J. Mater. Sci. Technol. 2021, 70, 113-124. [CrossRef]

13. Hrabe, N.; Quinn, T. Effects of processing on microstructure and mechanical properties of a titanium alloy (Ti-6Al-4V) fabricated using electron beam melting (EBM), Part 2: Energy input, orientation, and location. Mater. Sci. Eng. A 2013, 573, $271-277$. [CrossRef]

14. Silvestri, A.T.; Foglia, S.; Borrelli, R.; Franchitti, S.; Pirozzi, C.; Astarita, A. Electron beam melting of Ti6Al4V: Role of the process parameters under the same energy density. J. Manuf. Process. 2020, 60, 162-179. [CrossRef]

15. Juechter, V.; Scharowsky, T.; Singer, R.F.; Körner, C. Processing window and evaporation phenomena for Ti-6Al-4V produced by selective electron beam melting. Acta Mater. 2014, 76, 252-258. [CrossRef]

16. Shao, M.; Vijayan, S.; Nandwana, P.; Jinschek, J.R. The effect of beam scan strategies on microstructural variations in Ti-6Al-4V fabricated by electron beam powder bed fusion. Mater. Des. 2020, 196, 109165. [CrossRef]

17. Biffi, C.; Fiocchi, J.; Ferrario, E.; Fornaci, A.; Riccio, M.; Romeo, M.; Tuissi, A. Effects of the scanning strategy on the microstructure and mechanical properties of a TiAl6V4 alloy produced by electron beam additive manufacturing. Int. J. Adv. Manuf. Technol. 2020, 107, 1-12. [CrossRef]

18. Scharowsky, T.; Juechter, V.; Singer, R.F.; Körner, C. Influence of the Scanning Strategy on the Microstructure and Mechanical Properties in Selective Electron Beam Melting of Ti-6Al-4V. Adv. Eng. Mater. 2015, 17, 1573-1578. [CrossRef]

19. Dharmendra, C.; Alaghmandfard, R.; Hadadzadeh, A.; Amirkhiz, B.S.; Mohammadi, M. Influence of build orientation on small-scale properties of electron beam melted Ti-6Al-4V. Mater. Lett. 2020, 266, 126970. [CrossRef]

20. Bruno, J.; Rochman, A.; Cassar, G. Effect of Build Orientation of Electron Beam Melting on Microstructure and Mechanical Properties of Ti-6Al-4V. J. Mater. Eng. Perform. 2017, 26, 692-703. [CrossRef]

21. Seifi, M.; Dahar, M.; Aman, R.; Harrysson, O.; Beuth, J.; Lewandowski, J.J. Evaluation of Orientation Dependence of Fracture Toughness and Fatigue Crack Propagation Behavior of As-Deposited ARCAM EBM Ti-6Al-4V. JOM 2015, 67, 597-607. [CrossRef]

22. Gong, X.; Cui, Y.; Wei, D.; Liu, B.; Liu, R.; Nie, Y.; Li, Y. Building direction dependence of corrosion resistance property of Ti-6Al-4V alloy fabricated by electron beam melting. Corros. Sci. 2017, 127, 101-109. [CrossRef]

23. Gupta, A.; Bennett, C.J.; Sun, W. The role of defects and characterisation of tensile behaviour of EBM Additive manufactured Ti-6Al-4V: An experimental study at elevated temperature. Eng. Fail. Anal. 2021, 120, 105115. [CrossRef]

24. Mertová, K.; Džugan, J.; Roudnická, M.; Daniel, M.; Vojtěch, D.; Seifi, M.; Lewandowski, J.J. Build Size and Orientation Influence on Mechanical Properties of Powder Bed Fusion Deposited Titanium Parts. Metals 2020, 10, 1340. [CrossRef]

25. Raghavan, S.; Nai, M.L.S.; Wang, P.; Sin, W.J.; Wei, J.; Li, T. Heat treatment of electron beam melted (EBM) Ti-6Al-4V: Microstructure to mechanical property correlations. Rapid Prototyp. J. 2018, 24, 774-783. [CrossRef]

26. Galarraga, H.; Warren, R.J.; Lados, D.A.; Dehoff, R.R.; Kirka, M.M.; Nandwana, P. Effects of heat treatments on microstructure and properties of Ti-6Al-4V ELI alloy fabricated by electron beam melting (EBM). Mater. Sci. Eng. A 2017, 685, 417-428. [CrossRef]

27. Zhai, Y.; Galarraga, H.; Lados, D.A. Microstructure, static properties, and fatigue crack growth mechanisms in Ti-6Al-4V fabricated by additive manufacturing: LENS and EBM. Eng. Fail. Anal. 2016, 69, 3-14. [CrossRef]

28. Ganor, Y.I.; Tiferet, E.; Vogel, S.C.; Brown, D.W.; Chonin, M.; Pesach, A.; Hajaj, A.; Garkun, A.; Samuha, S.; Shneck, R.Z.; et al. Tailoring Microstructure and Mechanical Properties of Additively-Manufactured Ti6Al4V Using Post Processing. Materials 2021, 14, 658. [CrossRef]

29. Wang, M.; Li, H.-Q.; Guo, H.; Feng, L.; Liu, S.-Y.; Fang, X.-Y. Evolution of microstructure and intervariant boundaries of $\alpha$ phase in electron beam melted and heat-treated Ti-6Al-4V alloy. Rare Met. 2020, 110, 1-9. [CrossRef]

30. Leon, A.; Levy, G.K.; Ron, T.; Shirizly, A.; Aghion, E. The effect of hot isostatic pressure on the corrosion performance of Ti-6Al-4 $\mathrm{V}$ produced by an electron-beam melting additive manufacturing process. Addit. Manuf. 2020, 33, 101039. [CrossRef]

31. Zhao, X.; Li, S.; Zhang, M.; Liu, Y.; Sercombe, T.B.; Wang, S.; Hao, Y.; Yang, R.; Murr, L.E. Comparison of the microstructures and mechanical properties of Ti-6Al-4V fabricated by selective laser melting and electron beam melting. Mater. Des. 2016, 95, 21-31. [CrossRef]

32. Liu, C.; Mai, Z.; Yan, D.; Jiang, M.; Dai, Y.; Wang, P.; Chen, Z.; Lao, C. Effect of Hot Isostatic Pressing on Microstructures and Mechanical Properties of Ti6Al4V Fabricated by Electron Beam Melting. Metals 2020, 10, 593. [CrossRef] 
33. Abu-Issa, A.; Lopez, M.; Pickett, C.; Escarcega, A.; Arrieta, E.; Murr, L.E.; Wicker, R.B.; Ahlfors, M.; Godfrey, D.; Medina, F. Effects of altered hot isostatic pressing treatments on the microstructures and mechanical performance of electron beam melted Ti-6Al-4V. J. Mater. Res. Technol. 2020, 9, 8735-8743. [CrossRef]

34. Ghods, S.; Schultz, E.; Wisdom, C.; Schur, R.; Pahuja, R.; Montelione, A.; Arola, D.; Ramulu, M. Electron Beam Additive Manufacturing of Ti6Al4V: Evolution of Powder Morphology and Part Microstructure with Powder Reuse. Materialia 2020, 9, 100631. [CrossRef]

35. Schur, R.; Ghods, S.; Wisdom, C.; Pahuja, R.; Montelione, A.; Arola, D.; Ramulu, M. Mechanical anisotropy and its evolution with powder reuse in Electron Beam Melting AM of Ti6Al4V. Mater. Des. 2021, 200, 109450. [CrossRef]

36. Galarraga, H.; Lados, D.A.; Dehoff, R.R.; Kirka, M.M.; Nandwana, P. Effects of the microstructure and porosity on properties of Ti-6Al-4V ELI alloy fabricated by electron beam melting (EBM). Addit. Manuf. 2016, 10, 47-57. [CrossRef]

37. Yue, H.-Y.; Peng, H.; Su, Y.-J.; Wang, X.-P.; Chen, Y.-Y. Microstructure and high-temperature tensile property of TiAl alloy produced by selective electron beam melting. Rare Met. 2021, 119, 1-10.

38. Yue, H.; Peng, H.; Li, R.; Qi, K.; Zhang, L.; Lin, J.; Su, Y. Effect of heat treatment on the microstructure and anisotropy of tensile properties of TiAl alloy produced via selective electron beam melting. Mater. Sci. Eng. A 2021, 803, 140473. [CrossRef]

39. Wimler, D.; Lindemann, J.; Reith, M.; Kirchner, A.; Allen, M.; Vargas, W.G.; Franke, M.; Klöden, B.; Weißgärber, T.; Güther, V.; et al. Designing advanced intermetallic titanium aluminide alloys for additive manufacturing. Intermetallics 2021, 131, 107109. [CrossRef]

40. Youn, S.-J.; Kim, Y.-K.; Kim, S.-W.; Lee, K.-A. Elevated temperature compressive deformation behaviors of $\gamma$-TiAl-based Ti-48Al$2 \mathrm{Cr}-2 \mathrm{Nb}$ alloy additively manufactured by electron beam melting. Intermetallics 2020, 124, 106859. [CrossRef]

41. Lin, B.; Chen, W.; Yang, Y.; Wu, F.; Li, Z. Anisotropy of microstructure and tensile properties of Ti-48Al-2Cr-2Nb fabricated by electron beam melting. J. Alloys Compd. 2020, 830, 154684. [CrossRef]

42. Kim, Y.-K.; Hong, J.K.; Lee, K.-A. Enhancing the creep resistance of electron beam melted gamma Ti- $48 \mathrm{Al}-2 \mathrm{Cr}-2 \mathrm{Nb}$ alloy by using two-step heat treatment. Intermetallics 2020, 121, 106771. [CrossRef]

43. Biamino, S.; Penna, A.; Ackelid, U.; Sabbadini, S.; Tassa, O.; Fino, P.; Pavese, M.; Gennaro, P.; Badini, C. Electron beam melting of Ti-48Al-2Cr-2Nb alloy: Microstructure and mechanical properties investigation. Intermetallics 2011, 19, 776-781. [CrossRef]

44. Kan, W.; Liang, Y.; Peng, H.; Chen, B.; Guo, H.; Lin, J. Microstructural Degradation of Ti-45Al-8Nb Alloy During the Fabrication Process by Electron Beam Melting. JOM 2017, 69, 2596-2601. [CrossRef]

45. Juechter, V.; Franke, M.M.; Merenda, T.; Stich, A.; Körner, C.; Singer, R.F. Additive manufacturing of Ti-45Al-4Nb-C by selective electron beam melting for automotive applications. Addit. Manuf. 2018, 22, 118-126. [CrossRef]

46. Tan, X.; Kok, Y.; Tan, Y.J.; Descoins, M.; Mangelinck, D.; Tor, S.B.; Leong, K.F.; Chua, C.K. Graded microstructure and mechanical properties of additive manufactured Ti-6Al-4V via electron beam melting. Acta Mater. 2015, 97, 1-16. [CrossRef]

47. Wang, P.; Tan, X.; Nai, M.L.S.; Tor, S.; Wei, J. Spatial and geometrical-based characterization of microstructure and microhardness for an electron beam melted Ti-6Al-4V component. Mater. Des. 2016, 95, 287-295. [CrossRef]

48. Al-Bermani, S.; Blackmore, M.; Zhang, W.; Todd, I. The Origin of Microstructural Diversity, Texture, and Mechanical Properties in Electron Beam Melted Ti6Al4V. Metall. Mater. Trans. A Phys. Metall. Mater. Sci. 2010, 41, 3422-3434. [CrossRef]

49. Hrabe, N.; Quinn, T. Effects of processing on microstructure and mechanical properties of a titanium alloy (Ti-6Al-4V) fabricated using electron beam melting (EBM), part 1: Distance from build plate and part size. Mater. Sci. Eng. A 2013, 573, 264-270. [CrossRef]

50. Jiang, J.; Ren, Z.; Ma, Z.; Zhang, T.; Zhang, P.; Zhang, D.Z.; Mao, Z. Mechanical properties and microstructural evolution of TA15 Ti alloy processed by selective laser melting before and after annealing. Mater. Sci. Eng. A 2020, 772, 138742. [CrossRef]

51. Wu, X.; Cai, C.; Yang, L.; Liu, W.; Li, W.; Li, M.; Liu, J.; Zhou, K.; Shi, Y. Enhanced mechanical properties of Ti-6Al-2Zr-1Mo-1V with ultrafine crystallites and nano-scale twins fabricated by selective laser melting. Mater. Sci. Eng. A 2018, 738, 10-14. [CrossRef]

52. $\mathrm{Xu}, \mathrm{Y}$.; Liu, E.; Wei, S. Investigation on tensile fracture properties of TA15 specimen formed by selective electron beam melting. Mater. Sci. Eng. A 2020, 773, 138826. [CrossRef]

53. Guschlbauer, R.; Momeni, S.; Osmanlic, F.; Körner, C. Process development of $99.95 \%$ pure copper processed via selective electron beam melting and its mechanical and physical properties. Mater. Charact. 2018, 143, 163-170. [CrossRef]

54. Rafi, H.; Nadimpalli, K.; Gong, H.; Starr, T.; Stucker, B. Microstructures and Mechanical Properties of Ti6Al4V Parts Fabricated by Selective Laser Melting and Electron Beam Melting. J. Mater. Eng. Perform. 2013, 22, 3872-3883. [CrossRef] 